\title{
Area-selective atomic layer deposition of noble metals: Polymerized fluorocarbon layers as effective growth inhibitors ${ }^{\circledR}$
}

Cite as: J. Vac. Sci. Technol. A 39, 022402 (2020); https://doi.org/10.1116/6.0000701

Submitted: 08 October 2020 • Accepted: 05 January 2021 • Published Online: 29 January 2021

(iD) Petro Deminskyi, Ali Haider, Hamit Eren, et al.

\section{COLLECTIONS}

Paper published as part of the special topic on Special Topic Collection on Area Selective Deposition

EP This paper was selected as an Editor's Pick
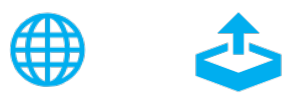

\section{ARTICLES YOU MAY BE INTERESTED IN}

Next generation nanopatterning using small molecule inhibitors for area-selective atomic layer deposition

Journal of Vacuum Science \& Technology A 39, 021002 (2021); https://

doi.org/10.1116/6.0000840

Area-selective molecular layer deposition of nylon 6,2 polyamide: Growth on carbon and inhibition on silica

Journal of Vacuum Science \& Technology A ASD2020, 023204 (2020); https://

doi.org/10.1116/6.0000769

Area-selective atomic layer deposition enabled by competitive adsorption

Journal of Vacuum Science \& Technology A ASD2020, 062411 (2020); https://

doi.org/10.1116/6.0000497

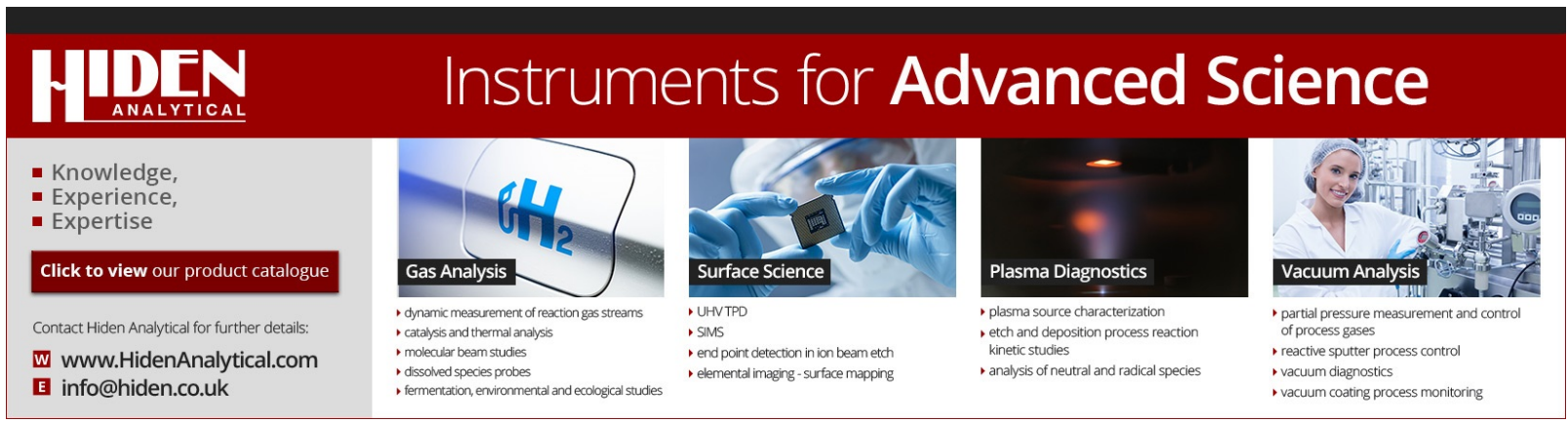




\title{
Area-selective atomic layer deposition of noble metals: Polymerized fluorocarbon layers as effective growth inhibitors
}

\author{
Cite as: J. Vac. Sci. Technol. A 39, 022402 (2021); doi: $10.1116 / 6.0000701$ \\ Submitted: 8 October 2020 . Accepted: 5 January 2021 . \\ Published Online: 29 January 2021
}

Petro Deminskyi, ${ }^{7}$ (D) Ali Haider, ${ }^{7}$ Hamit Eren, ${ }^{2}$ Talha M. Khan, ${ }^{7}$ and Necmi Biyikli ${ }^{3, a)}$ (D)

\author{
AFFILIATIONS \\ ${ }^{1}$ UNAM - Institute of Materials Science and Nanotechnology, Bilkent University, Ankara 06800, Turkey \\ ${ }^{2}$ Department of Chemical Engineering, Delft University of Technology, van der Maasweg 9, 2629 HZ Delft, The Netherlands \\ ${ }^{3}$ Department of Electrical and Computer Engineering, University of Connecticut, 371 Fairfield Way, Storrs, Connecticut 06269-4157
}

Note: This paper is a part of the Special Topic Collection on Area Selective Deposition.

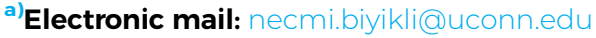

\begin{abstract}
The increasingly complex nanoscale three-dimensional and multilayered structures utilized in nanoelectronic, catalytic, and energy conversion/storage devices necessitate novel substrate-selective material deposition approaches featuring bottom-up and self-aligned precision processing. Here, we demonstrate the area-selective atomic layer deposition (AS-ALD) of two noble metals, Pt and Pd, by using a plasma-polymerized fluorocarbon layer as growth inhibition surfaces. The contact angle, $\mathrm{x}$-ray photoelectron spectroscopy (XPS), and scanning electron microscopy measurements were performed to investigate the blocking ability of polymerized fluorocarbon $\left(\mathrm{CF}_{\mathrm{x}}\right)$ layers against ALD-grown metal films. Both Pt and Pd showed significant nucleation delays on fluorocarbon surfaces. Self-aligned film deposition is confirmed using this strategy by growing $\mathrm{Pt}$ and $\mathrm{Pd}$ on the microscale lithographically patterned $\mathrm{CF}_{\mathrm{x}} / \mathrm{Si}$ samples. $\mathrm{CF}_{\mathrm{x}}$ blocking layer degradation during ozone exposure was analyzed using XPS measurements, which confirmed the oxygen physisorption as the main responsible surface reaction with further hydroxyl group formation on the $\mathrm{CF}_{\mathrm{x}}$ surface. Our work reveals that the $\mathrm{CF}_{\mathrm{x}}$ layer is compatible with an ozone coreactant until the blocking polymer cannot withstand oxygen physisorption. Our results could potentially be used to investigate and develop radical-assisted AS-ALD processes for a wider selection of materials.
\end{abstract}

Published under license by AVS. https://doi.org/10.1116/6.0000701

\section{INTRODUCTION}

Atomic-scale precision manufacturing of next-generation complex three-dimensional (3D) device structures necessitates the development of highly selective bottom-up material deposition strategies. As opposed to the conventional top-down approaches, area-selective deposition (ASD) provides self-aligned processing capability, which enhances the structural precision, while reducing the overall fabrication complexity. The relatively recent efforts in area-selective atomic layer deposition (AS-ALD) unveiled the significant potential of ALD as a bottom-up material synthesis technique, which can be engineered toward achieving surface selectivity. ${ }^{1-5}$ Being a surface-chemistry driven vapor-phase synthesis method, ALD features iterative self-limiting growth cycles based on lowtemperature ligand-exchange reactions. ${ }^{6,7}$ The resulting deposition is highly controllable with submonolayer thickness accuracy, along with excellent 3D conformity and large-area uniformity. ${ }^{8-14}$ The main target of AS-ALD efforts is to combine the unique features of ALD with surface selectivity, potentially leading to a versatile self-aligned fabrication toolbox.

Among others, the area-deactivation approach became the main AS-ALD strategy, where self-assembled monolayers (SAMs) or various polymer films are utilized as growth blocking surfaces. ${ }^{15,16}$ This way, selective deposition has been reported for oxides, ${ }^{4,17-19}$ $\left(\mathrm{Al}_{2} \mathrm{O}_{3}, \mathrm{SiO}_{2}, \mathrm{TiO}_{2}\right.$, and $\left.\mathrm{ZnO}\right)$ and metals ${ }^{20-23}(\mathrm{Pt}, \mathrm{Pd}, \mathrm{Ru}, \mathrm{Rh}, \mathrm{Ir}$, and $\mathrm{Co}$ ). Despite the promising results with various SAM chemistries, this approach suffered mainly from the difficulty in defect-free SAM synthesis, relatively long synthesis time, and CMOS compatibility. ${ }^{4,24-26}$ The latest reports by Bent et al. show that the time for SAM deposition reduces significantly with vapor-phase 
techniques compared with conventional liquid-phase synthesis and yet provides sufficient blocking performance for conventional thermal AS-ALD processes. ${ }^{1,27}$ However, both SAM and polymer blocking layers tend to degrade fairly quickly when radical-enhanced coreactants are utilized including plasmas and ozone. This incompatibility with energetic coreactants limits their use to merely thermal-ALD processes, excluding some critical materials. ${ }^{28,29}$

Platinum $(\mathrm{Pt})$ and palladium $(\mathrm{Pd})$ are among the most widely employed noble metals not only for CMOS logic and memory device fabrication ${ }^{30,31}$ but also for catalysis, ${ }^{32}$ energy conversion, ${ }^{33}$ chemical sensing, ${ }^{34,35}$ and energy storage. ${ }^{36}$ Selective deposition of these noble metals is significantly needed for the fabrication of selfaligned metal-contact placement in 3D nanoscale device structures. Reports on AS-ALD of Pd are mostly related to the controlled synthesis of $\mathrm{Pd} / \mathrm{Pt}$ core-shell nanoparticles using SAMs as blocking layers. ${ }^{37}$ On the other hand, former efforts related to the AS-ALD of Pt include (i) electron-beam induced deposition, ${ }^{38}$ which has compatibility issues for large areas and high-aspect-ratio structures, (ii) use of PMMA and polyimide (PI) blocking layers for thermal Pt-ALD that degrade under radical/plasma exposure, ${ }^{39}$ and (iii) topographically selective Pt-ALD on the vertical sidewalls of fin structures via ion-implanted ultrathin fluorocarbon films as growth inhibition horizontal surfaces. ${ }^{2}$ Selective noble-metal ALD featuring energetic coreactants such as ozone are yet missing. Growth inhibitors needed for such energetic ALD processes should ideally exhibit sufficient radical resistance, a defect/pinhole-free microstructure, CMOS-compatibility, ease of deposition, and thermal stability. ${ }^{15}$

Our previous work on AS-ALD of metal-oxide films where we used inductively coupled plasma (ICP)-polymerized fluorocarbon $\left(\mathrm{CF}_{\mathrm{x}}\right)$ coatings as blocking layers showed effective $\mathrm{ZnO}$ growth inhibition with self-aligned patterning, while no growth blocking efficiency was observed for $\mathrm{TiO}_{2}{ }^{40,41}$ The utilization of a CMOSstandard plasma-polymerized $\mathrm{CF}_{\mathrm{x}}$ film along with its relative ease of control revealed this approach with significant potential. In this work, we demonstrate that polymerized fluorocarbon surfaces can function as effective growth inhibitors for ALD-grown Pt and Pd films as well. Besides providing successful growth blocking for $\mathrm{Pt}$ and Pd, ozone-assisted Pt-ALD experiments revealed that polymerized $\mathrm{CF}_{\mathrm{x}}$ layers are also ozone-compatible. To the best of our knowledge, this is the first demonstration of an AS-ALD process utilizing ozone as a coreactant for noble metals. When compared with the ion-implanted ultrathin $\mathrm{CF}_{\mathrm{x}}$ blocking layers, ${ }^{2}$ our approach provides a complementary CMOS-compatible solution to inhibit $\mathrm{Pt}$ and Pd deposition on nonhorizontal surfaces of 3D nanostructures. This strategy might pave the way for the selective deposition of alternate materials, which necessitate energetic coreactants.

\section{EXPERIMENT}

\section{A. Film growth}

The $\mathrm{CF}_{\mathrm{x}}$ layer was deposited on a commercial ICP etch reactor (SPTS MPX-ICP), conventionally used for the deep reactive ion etching (DRIE) process of Si wafers. The deposition of $\sim 60 \mathrm{~nm}$ of $\mathrm{CF}_{\mathrm{x}}$ was performed for $\sim 70 \mathrm{~s}$ using $\mathrm{C}_{4} \mathrm{~F}_{8}(99.998 \%$ purity, Linde) at a gas flow rate of $70 \mathrm{SCCM}$ under a $400 \mathrm{~W}$ radio frequency plasma power at $13.56 \mathrm{MHz}$. Si (100) reference control samples were solventcleaned (acetone, isopropyl alcohol, de-ionized water rinse, and $\mathrm{N}_{2}$ blow dry) and exposed to $\mathrm{O}_{2}$ plasma in an asher system $(100 \mathrm{~W}$, 50 SCCM) for 2 min before ALD of Pd in order to increase the concentration of hydroxyl groups on the substrate, which should eliminate any possible nucleation delays on the Si surface. ${ }^{40}$ The reference control samples for the Pt study were not pretreated in $\mathrm{O}_{2}$ plasma before the main Pt-ALD growth due to the ozone-based plasma process that increases the hydroxyl groups on the substrate during the deposition experiments. Pt and Pd deposition on bare and $\mathrm{CF}_{\mathrm{x}}$-coated $\mathrm{Si}$ (100) samples was accomplished by using trimethyl (methylcyclopentadienyl) platinum(IV) $\left(\mathrm{MeCpPtMe}_{3}\right)$ and palladium(II) hexafluoroacetylacetonate $\left[\mathrm{Pd}(\mathrm{hfac})_{2}\right]$ as metal precursors. ${ }^{42,43}$ Ozone $\left(\mathrm{O}_{3}\right)$ and formalin $\left(\mathrm{CH}_{2} \mathrm{O}\right)$ were utilized as coreactants for Pt and Pd growth, respectively. ${ }^{44,45} \mathrm{O}_{3}$ was produced from a pure $\mathrm{O}_{2}$ flow with a Veeco/Cambridge NanoTech Savannah Ozone Generator. ALD experiments with different cycle numbers were carried out at 150 and $200^{\circ} \mathrm{C}$ for $\mathrm{Pt}$ and $\mathrm{Pd}$, respectively, using a Savannah S100 ALD reactor (Veeco/CambridgeNanoTech Inc.) and $\mathrm{N}_{2}$ as the carrier and purge gas. The unit ALD growth cycle of Pt consisted of $\mathrm{MeCpPtMe}_{3}$ pulse (0.2 s), $\mathrm{N}_{2}$ purge (15 s), ozone pulse $(0.1 \mathrm{~s})$, and $\mathrm{N}_{2}$ purge $(15 \mathrm{~s})$. The $\mathrm{MeCpPtMe}_{3}$ precursor was preheated to $65^{\circ} \mathrm{C}$ and stabilized at this temperature to transport the $\mathrm{MeCpPtMe}_{3}$ vapor to the reaction chamber. On the other hand, the unit ALD cycle of $\mathrm{Pd}$ consisted of a $\mathrm{Pd}(\mathrm{hfac})_{2}$ pulse $(0.4 \mathrm{~s}), \mathrm{N}_{2}$ purge $(10 \mathrm{~s})$, formalin pulse $(0.15 \mathrm{~s})$, and $\mathrm{N}_{2}$ purge $(10 \mathrm{~s})$. The $\mathrm{Pd}(\mathrm{hfac})_{2}$ precursor was preheated to $70{ }^{\circ} \mathrm{C}$ and stabilized at this temperature prior to the deposition experiments. Formalin was kept at room temperature during the growth. The total stabilization time before growth for both $\mathrm{Pt}$ and $\mathrm{Pd}$ was $\sim 20 \mathrm{~min}$.

\section{B. Film characterization and patterning}

Contact angles of bare and $\mathrm{CF}_{\mathrm{x}}$-coated $\mathrm{Si}$ (100) substrates have been measured before and after ALD growth cycles, using the static contact angle measurement setup (OCA 30). A $4 \mu$ l-water droplet was dropped on the sample surfaces to measure the contact angle. Film thicknesses of $\mathrm{CF}_{\mathrm{x}}$ were determined using a variable angle spectroscopic ellipsometer (V-VASE, J.A. Woollam Co. Inc., Lincoln, NE), which was coupled with a rotating analyzer and xenon light source. Ellipsometric spectra were collected at three angles of incidence $\left(65^{\circ}, 70^{\circ}\right.$, and $\left.75^{\circ}\right)$ to yield adequate sensitivity over the full spectral range. Film thickness values were extracted by fitting the spectroscopic ellipsometer data using the Cauchy model, while the substrate was set as default $\mathrm{Si}(100)$ in V-Vase Woollam software. Elemental composition and chemical bonding states of the metal films were obtained by $\mathrm{x}$-ray photoelectron spectroscopy (XPS) measurements using a Thermo Scientific K-Alpha spectrometer (Thermo Fisher Scientific) with a monochromatized $\mathrm{Al} \mathrm{K \alpha}$ $\mathrm{X}$-ray source (a spot size of $\sim 400 \mu \mathrm{m}$ ). All peaks in XPS survey scans are referenced to the $\mathrm{C} 1 \mathrm{~s}$ peak for charge correction, and quantification of survey scans has been performed using AVANTAGE software. The surface morphologies of the Pt and Pd-coated samples were determined using a high-resolution FIB-SEM system (FEI, Nova 600i Nanolab), and the cluster size was determined using "IMAGEJ" software. To pattern $\mathrm{CF}_{\mathrm{x}}$ via lithography on $\mathrm{Si}$ (100) substrates, $\sim 1.4 \mu \mathrm{m}$ of AZ5214 photoresist (Microchemicals $\mathrm{GmbH}$ ) was spun on the wafer and was patterned into a checkerboard and parallel striped lines using a suitable photomask and photolithography. 
The wafer was then hard baked at $110^{\circ} \mathrm{C}$ for $5 \mathrm{~min}$, followed by the ICP polymerization process in the ICP reactor. Once the deposition was complete, the wafer was soaked into acetone for the lift-off process of $\mathrm{CF}_{\mathrm{x}}$ layer portions on top of the patterned photoresist. The resulting wafer with a patterned $\mathrm{CF}_{\mathrm{x}}$ layer was solvent-cleaned before subsequent metal-ALD growth experiments. An XPS line scan was performed on the resulting Pt and Pd-coated samples to determine the selectivity performance as a function of ALD cycles, using the same XPS system with a spot size of $\sim 100 \mu \mathrm{m}$, the scanning step size, and scanning points of $41 / 43 \mu \mathrm{m}$ and $100 / 176$ for $\mathrm{Pt} / \mathrm{Pd}$, respectively. The structural analysis of the ALD-grown $\mathrm{Pt}$ and $\mathrm{Pd}$ thin films was performed using grazing-incidence $\mathrm{X}$-ray diffraction (GIXRD) patterns that were recorded in an X'Pert PRO
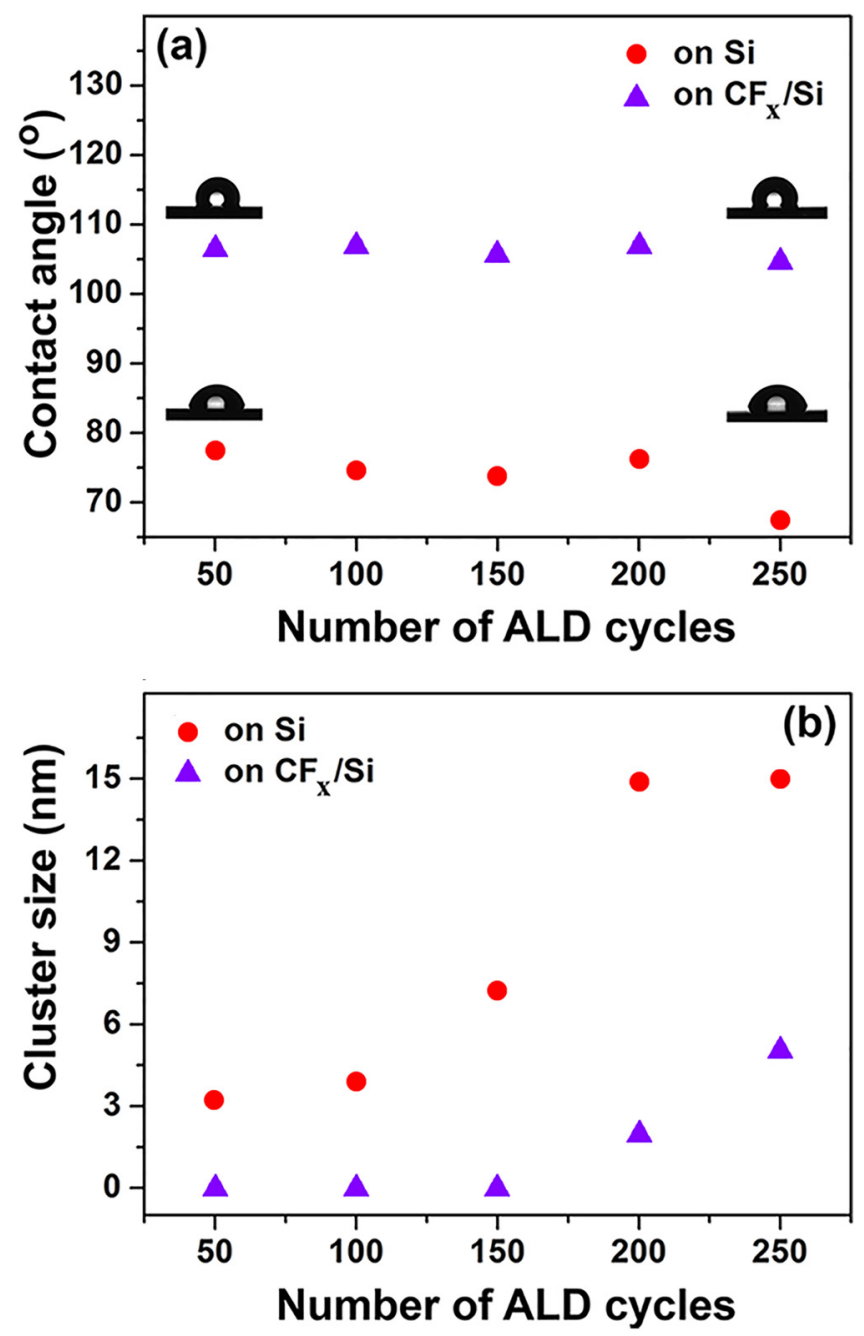

FIG. 1. Variation in (a) contact angle and (b) average Pt cluster size as a function of ALD growth cycles on fluorocarbon coated and bare Si (100) substrates. Exhibiting a relatively constant contact angle, the fluorocarbon surface shows Pt-nucleation inhibition character for more than 150 ALD cycles.
MRD diffractometer (PANalytical B.V., Almelo, The Netherlands) using $\mathrm{Cu} \mathrm{K \alpha}$ radiation. Data were obtained within the $2 \theta$ range of $30-90^{\circ}$ by the summation of ten scans, which were performed using a $0.1^{\circ}$ step size and $15 \mathrm{~s}$ counting time. Interplanar spacing
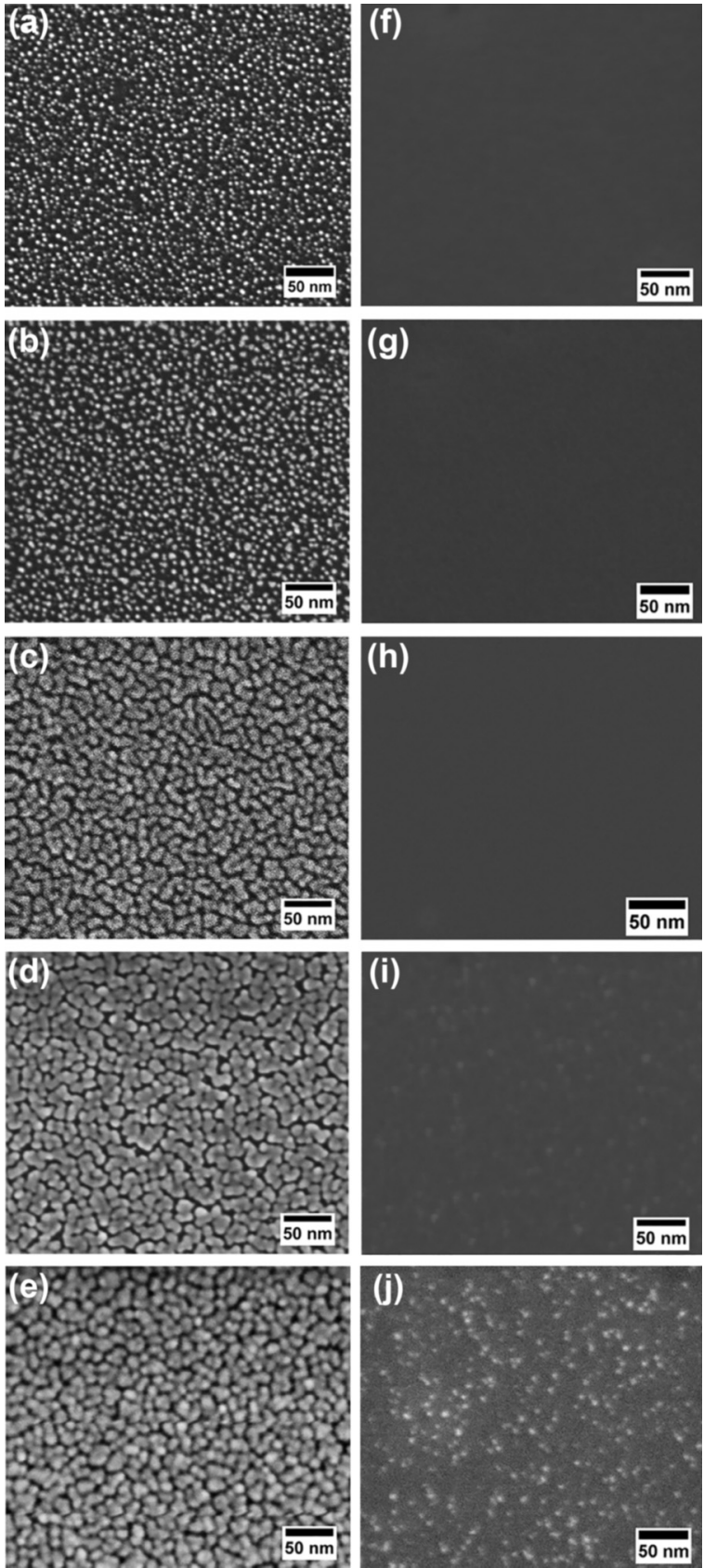

FIG. 2. SEM images of (a)-(e) bare $\mathrm{Si}(100)$ and (f)-(j) $\mathrm{CF}_{x} / \mathrm{Si}(100)$ sample surfaces at various stages in Pt-ALD growth experiments (a) and (f) 50 cycles; (b) and (g) 100 cycles; (c) and (h) 150 cycles; (d) and (i) 200 cycles; and (e) and (j) 250 cycles. 
TABLE I. Variation in $\mathrm{Pt}$ and $\mathrm{O}$ at. $\%$ on $\mathrm{CF}_{x} / \mathrm{Si}$ samples and the selectivity value as a function of ALD cycles.

\begin{tabular}{lccc}
\hline \hline \multirow{2}{*}{$\begin{array}{l}\text { Number of } \\
\text { ALD cycles }\end{array}$} & \multicolumn{2}{c}{$\mathrm{CF}_{\mathrm{x}} / \mathrm{Si}$} & $\begin{array}{c}\mathrm{Pt} / \mathrm{Si} \text { to } \mathrm{Pt} / \mathrm{CF}_{\mathrm{x}} \\
\text { selectivity }\end{array}$ \\
\cline { 2 - 3 } 50 & $\mathrm{Pt}$ at. \% & $\mathrm{O}$ at. \% & $\sim 1$ \\
100 & 0.01 & 1.03 & \\
150 & 0.01 & 1.57 & $\sim 0.99$ \\
200 & 0.1 & 1.81 & $\sim 0.95$ \\
250 & 2.62 & 2.17 & \\
\hline \hline
\end{tabular}
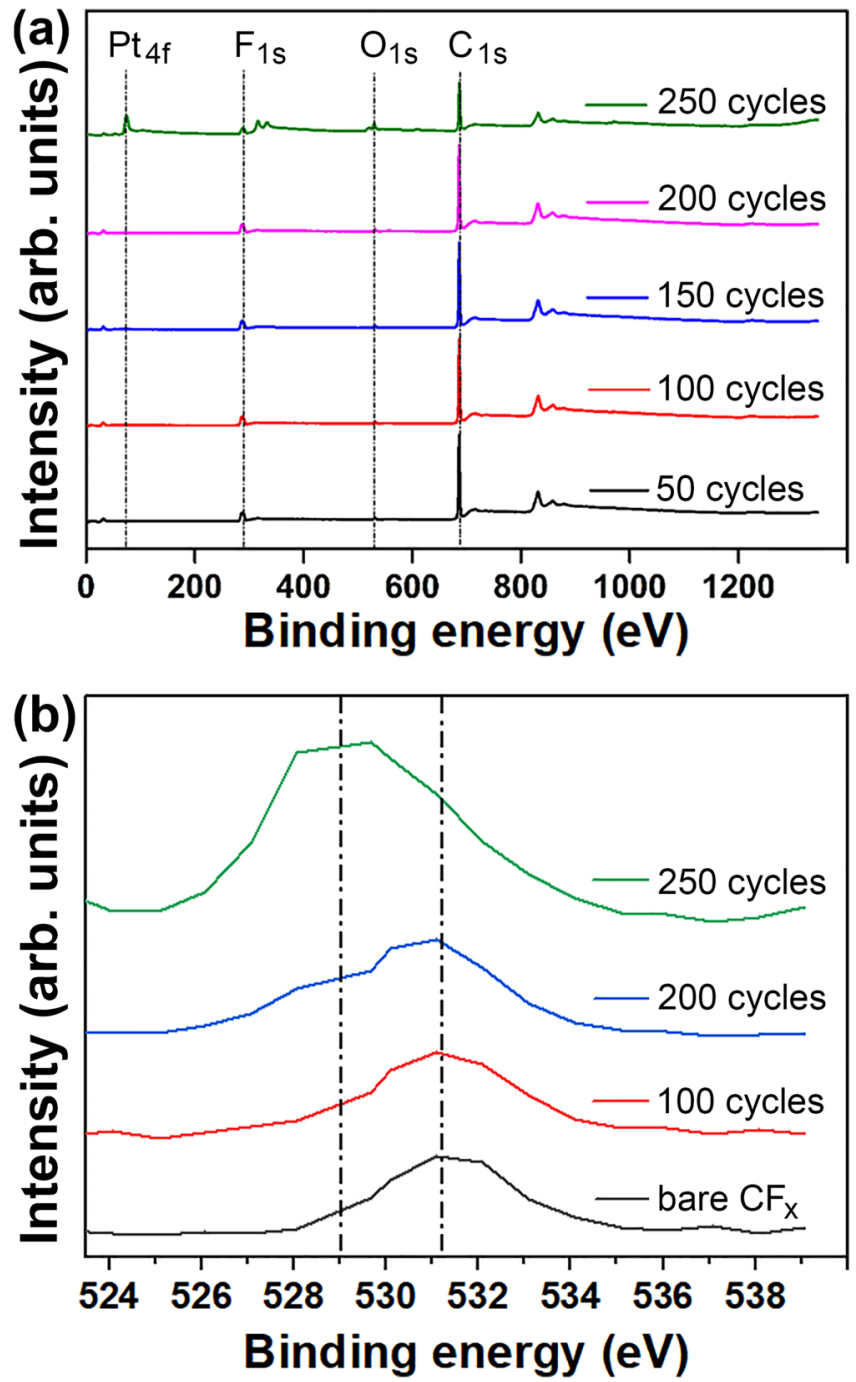

FIG. 3. (a) XPS survey scans of the $\mathrm{CF}_{\mathrm{x}} / \mathrm{Si}(100)$ sample after $50,100,150$, 200 , and 250 Pt-ALD cycles, depicting a 200-cycle nucleation delay on the polymerized $\mathrm{CF}_{\mathrm{x}}$ surface; (b) HR-XPS scans of $\mathrm{O} 1 \mathrm{~s}$ obtained on $\mathrm{CF}_{\mathrm{x}} / \mathrm{Si}$ (100) after 0, 100, 200, and 250 Pt-ALD cycles. $\left(d_{h k l}\right)$ values were calculated from peak positions using Bragg's law. The lattice parameter was calculated by using the experimentally extracted $d_{h k l}$ values in Eq. (1), which relates the interplanar spacing $\left(d_{h k l}\right)$, miller indices $(h k l)$, and the lattice parameter $\left(a_{0}\right)$ to a face-centered cubic (fcc) crystal system,

$$
d_{h k l}=\frac{a_{0}}{\sqrt{h^{2}+k^{2}+l^{2}}}
$$

To determine the growth selectivity values for Pt and Pd as a function of ALD cycles, we used Eq. (2), which is based on the measured XPS elemental concentrations of $\mathrm{Pt}$ or $\mathrm{Pd}$ on $\mathrm{CF}_{\mathrm{x}}$ (nongrowth) and $\mathrm{Si}$ (growth) surfaces,

$$
\text { Selectivity }=\frac{A_{\mathrm{Si}}-B_{\mathrm{CFx}}}{A_{\mathrm{Si}}},
$$

where $A_{\mathrm{Si}}$ and $B_{\mathrm{CFx}}$ are the atomic percent of the ALD deposited material on $\mathrm{Si}$ and $\mathrm{CF}_{\mathrm{x}}$ surfaces, respectively. The sensitivity of our selectivity numbers is, therefore, limited by the XPS detection limit, which is typically around or slightly higher than 0.01 at. \%.
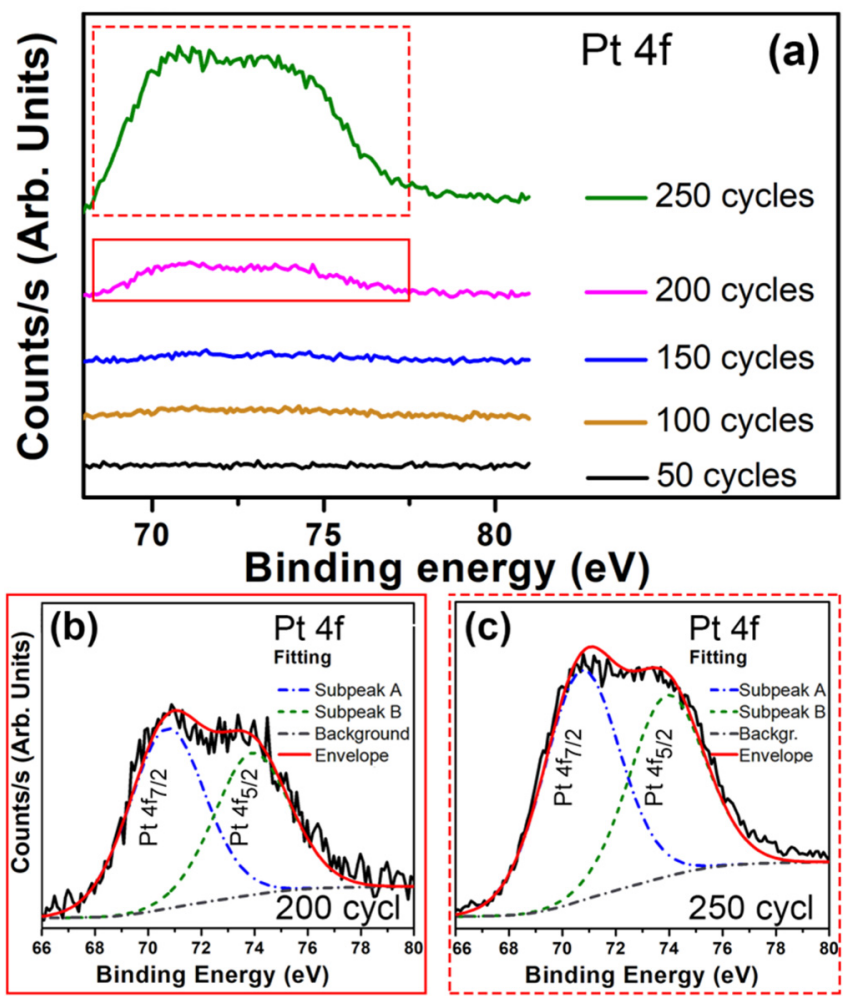

FIG. 4. HR-XPS survey scans of Pt 4 obtained on (a) $\mathrm{CF}_{x} / \mathrm{Si}$ (100) after 50 , 100, 150, 200, and 250 Pt-ALD cycles; (b) HR-XPS Pt $4 f$ peak fitting for the 200-cycle $\mathrm{CF}_{x} / \mathrm{Si}$ (100) sample; and (c) Pt 4 peak fitting for 250-cycle $\mathrm{CF}_{x} / \mathrm{Si}$ (100) sample. 


\section{RESULTS AND DISCUSSION}

\section{A. Pt nucleation and selectivity}

\section{Pt nucleation: $C F_{x}$ versus Si (100) surfaces}

In the first part of our selective deposition study, Pt film nucleation and growth behavior on $\mathrm{CF}_{\mathrm{x}}$ and $\mathrm{Si}$ surfaces via ozone-based low-temperature ALD are explored. Initial contact angles of $\mathrm{Si}$ and $\mathrm{CF}_{\mathrm{X}} / \mathrm{Si}$ samples before the ALD cycles were measured as $\sim 71^{\circ}$ and $\sim 114^{\circ}$, respectively. After the initial 50 ALD cycles, the contact angles on the same samples were measured as $77.4^{\circ}$ and $106.4^{\circ}$, respectively, marking an increase for $\mathrm{Si}$ and a decrease for $\mathrm{CF}_{\mathrm{x}}$ surfaces. The contact angle on $\mathrm{Si}(100)$ decreased to $\sim 67.4^{\circ}$ after 250 Pt-ALD cycles, while it remained almost unchanged for the $\mathrm{CF}_{\mathrm{x}}$-coated sample with a relatively narrow fluctuation between $\sim 104^{\circ}$ and $106^{\circ}$
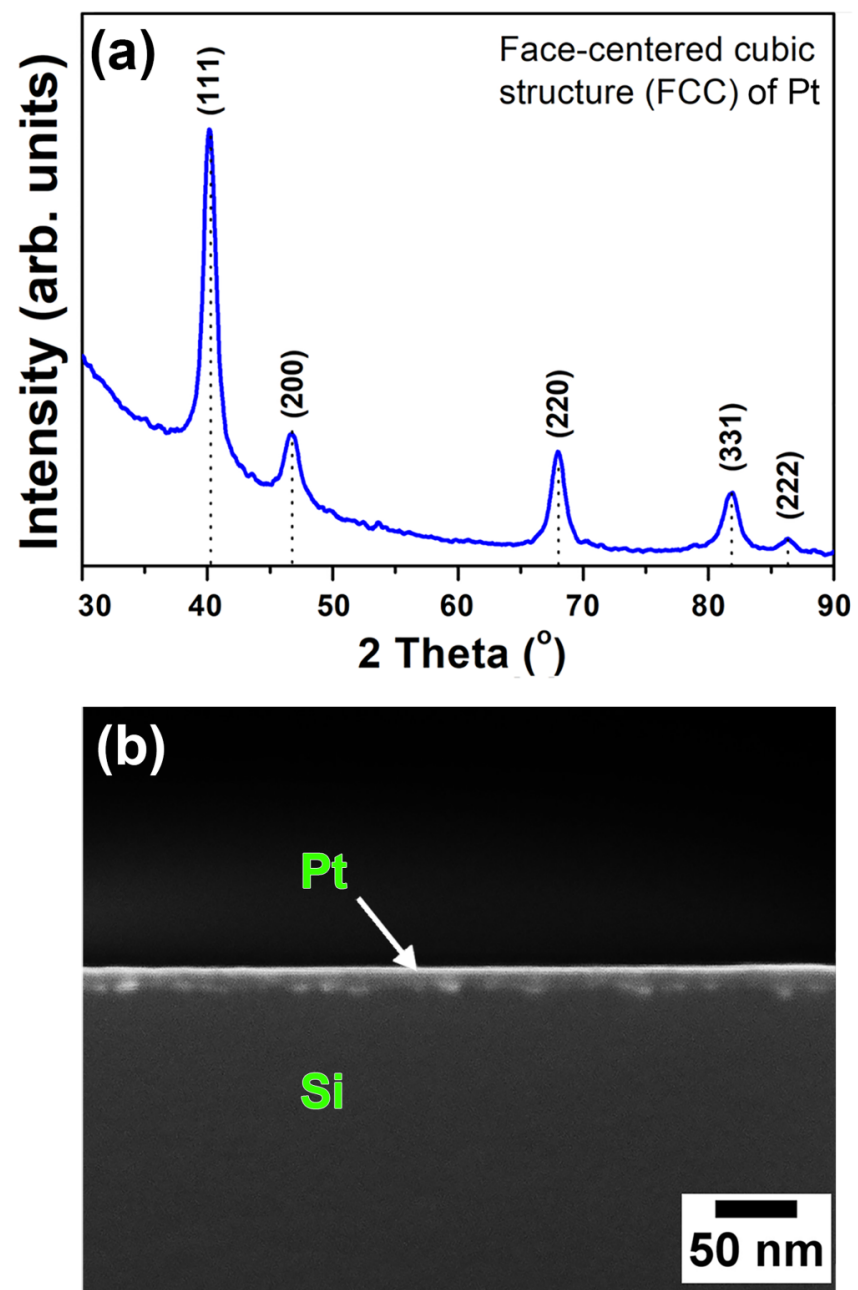

FIG. 5. (a) GIXRD pattern of the Pt film deposited on the Si(100) substrate at $150{ }^{\circ} \mathrm{C}$. (b) Cross-sectional SEM image of the Pt/Si sample showing the total thickness $(\sim 20 \mathrm{~nm})$ of the Pt film. (a)
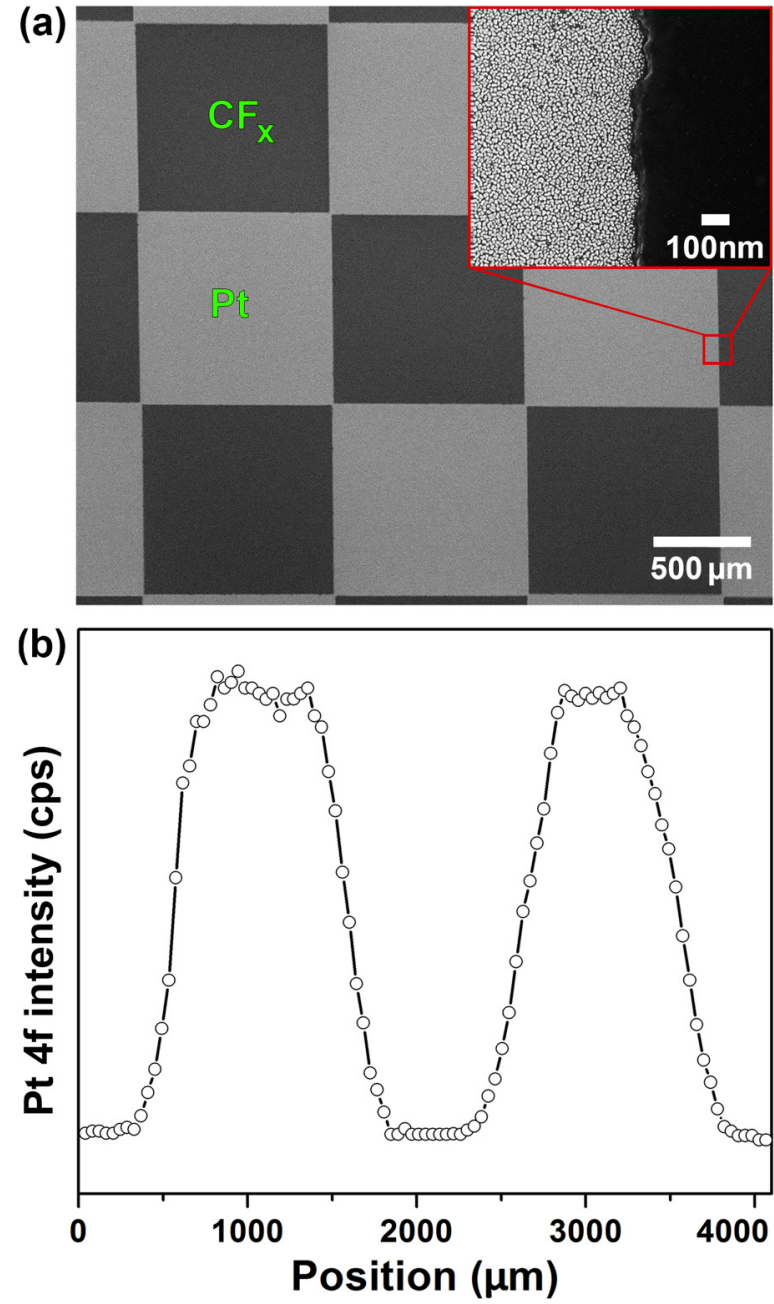

(c)

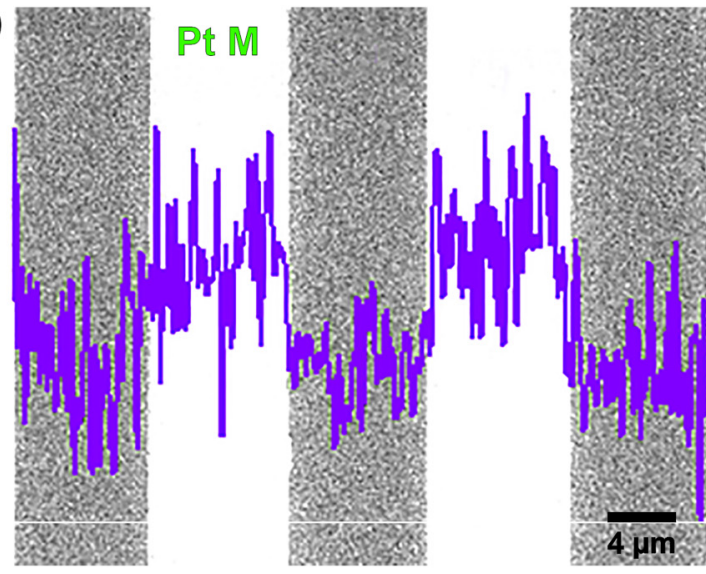

FIG. 6. (a) SEM image and (b) XPS Pt 4 line scan obtained from Pt-ALD grown on the mm-scale patterned $\mathrm{CF}_{\mathrm{X}} / \mathrm{Si}$ (100) sample. (c) EDX Pt M line scan superposed on the SEM image obtained from the $\mu \mathrm{m}-\mathrm{Scale}_{\mathrm{C}} \mathrm{CF}_{\mathrm{x}} / \mathrm{Si}$ (100) patterned sample after 180 Pt-ALD cycles. 
up to 250 cycles [Fig. 1(a)]. Subsequently, we analyzed the evolution of $\mathrm{Pt}$ nucleation by measuring the Pt-island/cluster size on $\mathrm{Si}$ and $\mathrm{CF}_{\mathrm{x}}$ samples as a function of ALD cycles. Figure 1(b) shows how the average Pt cluster size evolved on both sample surfaces with increasing the number of ALD cycles, which clearly indicates a considerable nucleation delay on the $\mathrm{CF}_{\mathrm{x}}$ surface. While no Pt clusters were detected up to 150 cycles, $\sim 2$ and $\sim 5 \mathrm{~nm}$ Pt clusters were observed on $\mathrm{CF}_{\mathrm{x}}$ samples after 200 and $250 \mathrm{ALD}$ cycles, respectively, with relatively low density and surface coverage with respect to the Si (100) reference samples. On the other hand, Pt nucleated easily on the Si (100) surface exhibiting high-density $\sim 3 \mathrm{~nm}$ sized Pt clusters after the initial 50 ALD cycles, which increased and saturated up to $\sim 15 \mathrm{~nm}$ for 200 and higher ALD cycles.

Figures 2(a)-2(j) show the obtained images from the Si (100) and $\mathrm{CF}_{\mathrm{x}}$ sample surfaces after 50,100, 150, 200, and 250 ALD cycles, respectively. The initial 50 cycle results clearly reveal successful Pt nucleation on Si (100) with an increase in both the Pt nanoparticle (NP) density and cluster size, leading toward coalescence into larger islands ( $\sim 15 \mathrm{~nm}$ for $200+$ cycles $)$ and an eventually complete surface coverage resulting in a continuous Pt film. However, in contrast to the bare Si (100) sample, the $\mathrm{CF}_{\mathrm{x}} / \mathrm{Si}$ sample surface is free from any HR-SEM-detectable $\mathrm{Pt}$ nucleation at the end of 150 ALD cycles. Pt nucleation on $\mathrm{CF}_{\mathrm{x}}$ becomes evident only after 200 ALD cycles with an initial average Pt-cluster diameter of $\sim 2 \mathrm{~nm}$ and a relatively nonuniform surface distribution. As a result, the initial Pt NP seeds on the $\mathrm{CF}_{\mathrm{x}}$ surface function as growth centers during further ALD cycles featuring half-cycle exposures of $\mathrm{C}_{9} \mathrm{H}_{16} \mathrm{Pt}$ and ozone.
The average Pt cluster size further increases to $\sim 5 \mathrm{~nm}$ at 250 ALD cycles, confirming the loss of $\mathrm{Pt}$ growth inhibition character of $\mathrm{CF}_{\mathrm{x}}$ surface beyond 200 cycles.

Table I summarizes how the platinum and oxygen content from the surface of the $\mathrm{CF}_{\mathrm{x}} / \mathrm{Si}$ and $\mathrm{Si}$ (100) samples evolves during ALD cycles via XPS survey scans. Other than the Pt and O content-more detailed information related to the elemental composition of $\mathrm{Si}, \mathrm{C}$, and $\mathrm{F}$ is presented in Tables SI and SII in the supplementary material. ${ }^{56}$ XPS measurements of the $\mathrm{CF}_{\mathrm{x}}$ sample surface show the absence of a detectable Pt signal for 50 and 100 ALD cycles. After 150 ALD cycles, a very weak Pt signal is detected, corresponding to only $\sim 0.01$ at. $\%$, which increases by almost an order of magnitude-but still relatively low ( $\sim 0.07$ at. \%) for 200 ALD cycles. A further increase in Pt-ALD cycles up to 250 cycles indicates a stronger increase in the Pt content to 2.6 at. \%, confirming the practical Pt nucleation onset for ALD cycles around 200.

The combination of the adsorption of the noble metal precursor and the use of reactive ozone starts to show its effect on the ICP-polymerized $\mathrm{CF}_{\mathrm{x}}$ surface only after 200 ALD growth cycles. XPS measurements of the $\mathrm{CF}_{\mathrm{x}}$-coated sample exposed to 250 Pt-ALD cycles show the oxygen content fluctuating within $\sim 2-4$ at. \%. It confirms the relative stability of the ICP-polymerized $\mathrm{CF}_{\mathrm{x}}$ surface against degradation during reactive ozone exposure until the formation of hydroxyl groups (that behave like nucleation centers for Pt growth) and the subsequently adsorbed Pt on the surface. To the best of our knowledge, this result represents the first demonstration of a selective ALD process featuring a reactive ozone coreactant for Pt deposition.
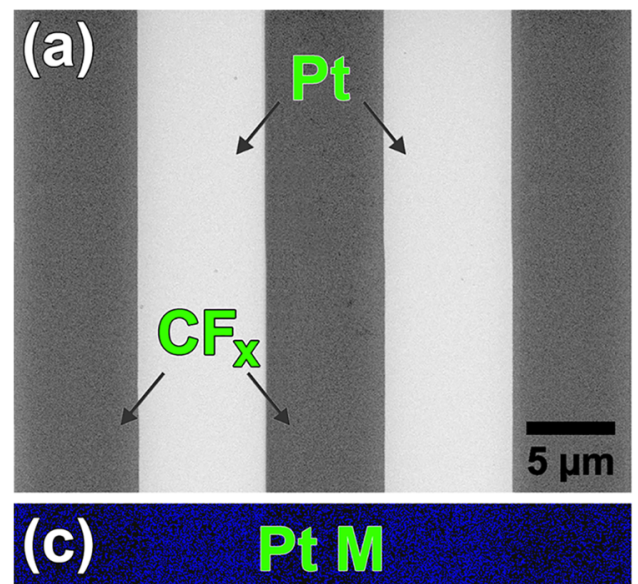

5 нm
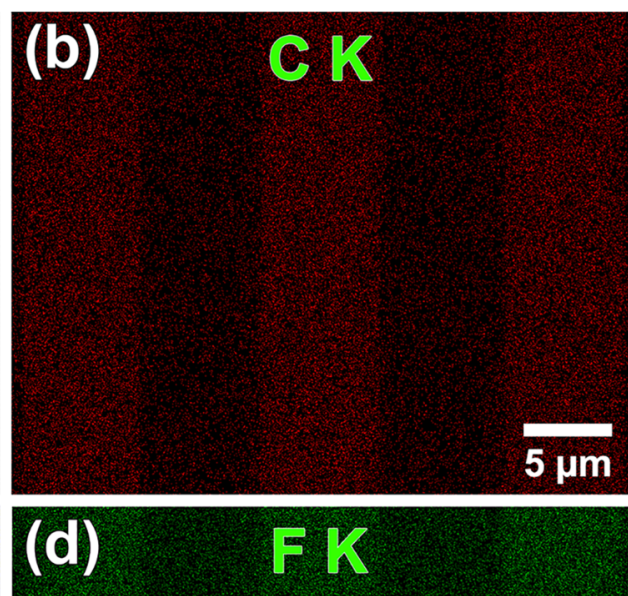

\section{)}

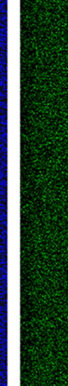

FIG. 7. SEM image of (a) $P t / C F_{x}$ self-aligned patterned sample after the 180-cycle Pt-ALD experiment. Elemental mapping of (b) C K, (c) Pt $M$, and (d) F K signals. 
Figure 3(a) shows the XPS survey scan results obtained for $\mathrm{CF}_{\mathrm{X}} / \mathrm{Si}$ samples recorded at 50,100,150, 200, and 250 ALD cycles. While detecting $\mathrm{C} 1 \mathrm{~s}, \mathrm{O} 1 \mathrm{~s}$, and $\mathrm{F}$ 1s peaks from the $\mathrm{CF}_{\mathrm{x}}$ surface, the absence of the Pt $4 \mathrm{f}$ peak confirms the successful Pt nucleation inhibition for more than 150 ALD cycles. These results confirm the effective nucleation inhibition behavior of ICP-polymerized $\mathrm{CF}_{\mathrm{x}}$ films as growth blocking surfaces for Pt deposition. Moreover, the XPS survey scan results provide excellent correlation with SEM observations as well as contact angle measurements and cumulatively approve that $\mathrm{CF}_{\mathrm{x}}$ inhibits the Pt nucleation process for $\sim 200$ growth cycles, which is equivalent to a growth blocking thickness of $\sim 17 \mathrm{~nm}$. The $\sim 0.99$ selectivity at 200 cycles drops to $\sim 0.95$ at 250 ALD cycles.

Figure 3(b) shows the analysis study on the reaction resistance of the fluorocarbon layer exposed to ozone-based growth reactions via investigating the $\mathrm{O} 1 \mathrm{~s}$ peaks on the $\mathrm{CF}_{\mathrm{x}} / \mathrm{Si}$ substrate before and after 100,200, and 250 cycles of Pt-ALD growth cycles from the measured XPS scans. $\mathrm{O} 1 \mathrm{~s}$ is detected on the $\mathrm{CF}_{\mathrm{x}}$ substrate before
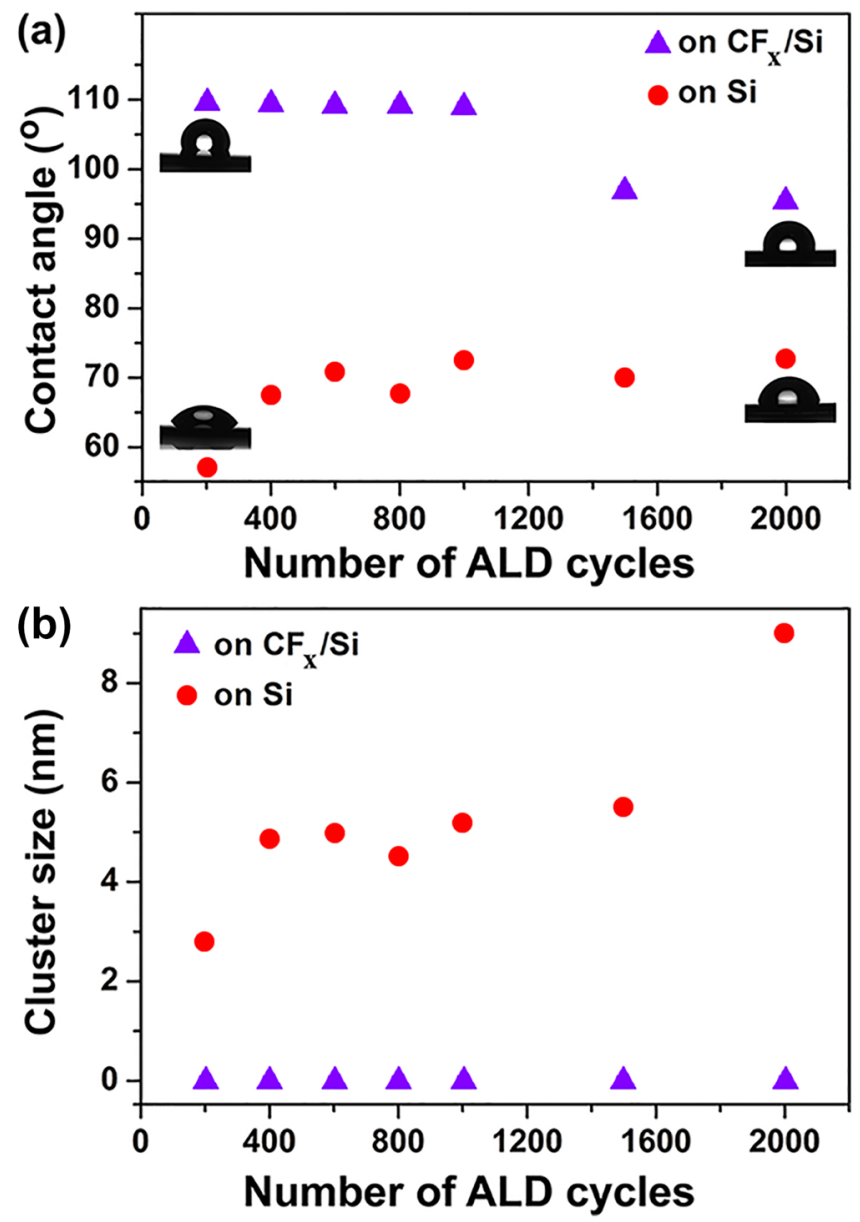

FIG. 8. Variation in (a) contact angle; (b) average Pd-cluster size with number of ALD cycles on $\mathrm{CF}_{\mathrm{x}} / \mathrm{Si}$ and bare Si (100) samples. and after Pt growth, with the $\mathrm{O}$ 1s peak located at $531.1 \mathrm{eV}$ (I) corresponds to hydroxyl groups $(\mathrm{OH})$ on the surface of $\mathrm{CF}_{\mathrm{x}}$ that is in good agreement with the hydroxide signal $(531.5 \pm 0.5 \mathrm{eV})$, which is a typical value for binding energies for oxides. ${ }^{46}$ We also note
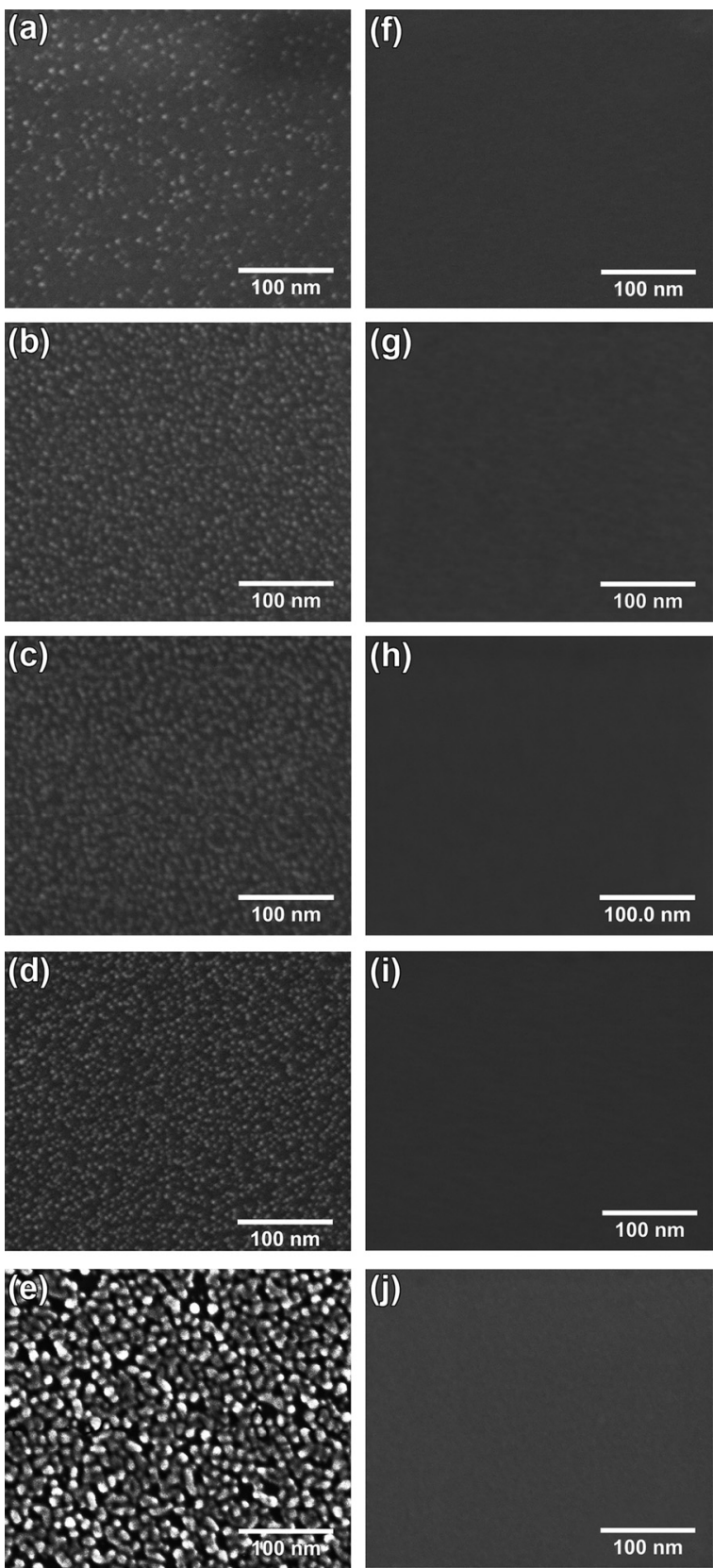

FIG. 9. HR-SEM images of the substrate surfaces of (a)-(e) bare Si (100) samples and (f)-(j) $\mathrm{CF}_{\mathrm{X}} / \mathrm{Si}(100)$ samples at various stages of the Pd-ALD experiment: (a) and (f) 200 cycles, (b) and (g) 600 cycles, (c) and (h) 1000 cycles, (d) and (i) 1500 cycles, and (e) and (j) 2000 cycles. 
another interesting observation: on the $\mathrm{CF}_{\mathrm{x}}$ surface, the $\mathrm{O}$ 1s peak is broadening to lower binding energies with the peak intensity at $529.7 \mathrm{eV}$ (II) for 250 cycles of Pt-ALD, which could be assigned to the oxygen atoms directly bound to metallic $\mathrm{Pt}^{47,48}$ The mechanism of the Pt nucleation on $\mathrm{CF}_{\mathrm{x}}$ is currently not fully understood. We hypothesize that during the ozone half-reaction, oxygen is slowly physisorbed onto the $\mathrm{CF}_{\mathrm{x}}$ film surface. This diffusion is likely enhanced during additional ozone exposure cycles. In the meantime, during the $\mathrm{MeCpPtMe}_{3}$ half-reaction, hydroxyl groups form on the centers of oxygen vacancies that create favorable nucleation centers for further $\mathrm{Pt}$ growth initiation. Although the hydroxyl groups are created on the $\mathrm{CF}_{\mathrm{x}}$ surface, the amount of $\mathrm{Pt}$ that could be chemisorbed on such active sites is still under the XPS detection limit up to 150 ALD cycles.

Figure 4 shows Pt $4 \mathrm{f}$ HR-XPS scans measured on $\mathrm{CF}_{\mathrm{x}} / \mathrm{Si}$ samples and HR-XPS scans taken after 50, 100, 150, 200, and 250 cycles of Pt-ALD. XPS measurements of $\mathrm{CF}_{\mathrm{x}}$-coated Si samples after 50, 100, 150, 200, and 250 cycles of Pt-ALD show no considerable Pt signal up to 200 cycles [Fig. 4(a) and Table SIII in the supplementary material]. ${ }^{56}$ At 200 and 250 cycles, we started to observe signals in the range of $67-79 \mathrm{eV}$ corresponding to Pt $4 \mathrm{f}$ peaks. After XPS data fitting, we deconvoluted the Pt $4 \mathrm{f}$ peak into two well-separated $(\Delta=\sim 3.3 \mathrm{eV})$ spin--orbit components with a height ratio of 1:0.77 [Figs. 4(b) and 4(c)]. For the 200-cycle sample, Pt $4 \mathrm{f}$ peaks centered at $70.7 \pm 0.2 \mathrm{eV}$ (subpeak A-Pt $4 \mathrm{f}_{7 / 2}$ ) and $74.0 \pm 0.2 \mathrm{eV}$ (subpeak B-Pt $4 \mathrm{f}_{5 / 2}$ ) are assigned to the metallic $\mathrm{Pt}(0)$ bonding. Likewise, we deconvoluted the Pt $4 \mathrm{f}$ peak for the 250 -cycle sample into two individual peaks centered at $70.7 \pm 0.2 \mathrm{eV}$ (subpeak A-Pt 4f $\mathrm{f}_{7 / 2}$ ) and $74.0 \pm 0.2 \mathrm{eV}$ (subpeak BPt $4 f_{5 / 2}$ ), which are assigned to the same metallic Pt. Pt $4 f_{7 / 2}$ and $P t$ $4 \mathrm{f}_{5 / 2}$ are not clearly separated from each other, which could be attributed to the platinum oxidation that resulted in the shoulder formation. ${ }^{49}$ Furthermore, the slightly lower binding energies $(70.7 \pm 0.2 \mathrm{eV})$ possibly indicate the presence of smaller Pt particles, which are also in good agreement with the cluster size dependence on the total ALD cycle number [Figs. $1(\mathrm{~b})$ and $2(\mathrm{~d})-2(\mathrm{j})]^{50}$ Additional information related to the Pt HR-XPS scans measured on $\mathrm{Si}$ samples is represented in the supplementary material, ${ }^{56}$ which is in good agreement with the observed trend on $\mathrm{CF}_{\mathrm{x}} / \mathrm{Si}$ (100) samples: oxide states within the initial 50-100 cycles were transformed to metallic states at higher ALD cycle numbers. The

TABLE II. Variation in Pd at. \% on $\mathrm{CF}_{\mathrm{X}} / \mathrm{Si}$ samples and the calculated selectivity value as a function of ALD cycles.

\begin{tabular}{lcc}
\hline \hline $\begin{array}{l}\text { Number of } \\
\text { ALD cycles }\end{array}$ & $\begin{array}{c}\mathrm{CF}_{\mathrm{x}} / \mathrm{Si} \\
\mathrm{Pd} \text { at. } \%\end{array}$ & $\begin{array}{c}\mathrm{Pd} / \mathrm{Si} \text { to } \mathrm{Pd} / \mathrm{CF}_{\mathrm{x}} \\
\text { selectivity }\end{array}$ \\
\hline 200 & 0.02 & $\sim 1$ \\
400 & 0.03 & \\
600 & 0.03 & \\
800 & 0.03 & \\
1000 & 0.02 & \\
1500 & 0.03 & \\
2000 & 0.12 & \\
\hline \hline
\end{tabular}

HR-XPS scans of Pt 4f on Si (100) are provided in Fig. S1 in the supplementary material. ${ }^{56}$

Another important observation was the thickness stability $(\sim 60 \mathrm{~nm})$ of $\mathrm{CF}_{\mathrm{x}}$ blocking layer, regardless of the Pt-ALD cycles that featured reactive ozone exposures. The absence of any decrease in $\mathrm{CF}_{\mathrm{x}}$ thickness under ozone cycles might be attributed to the
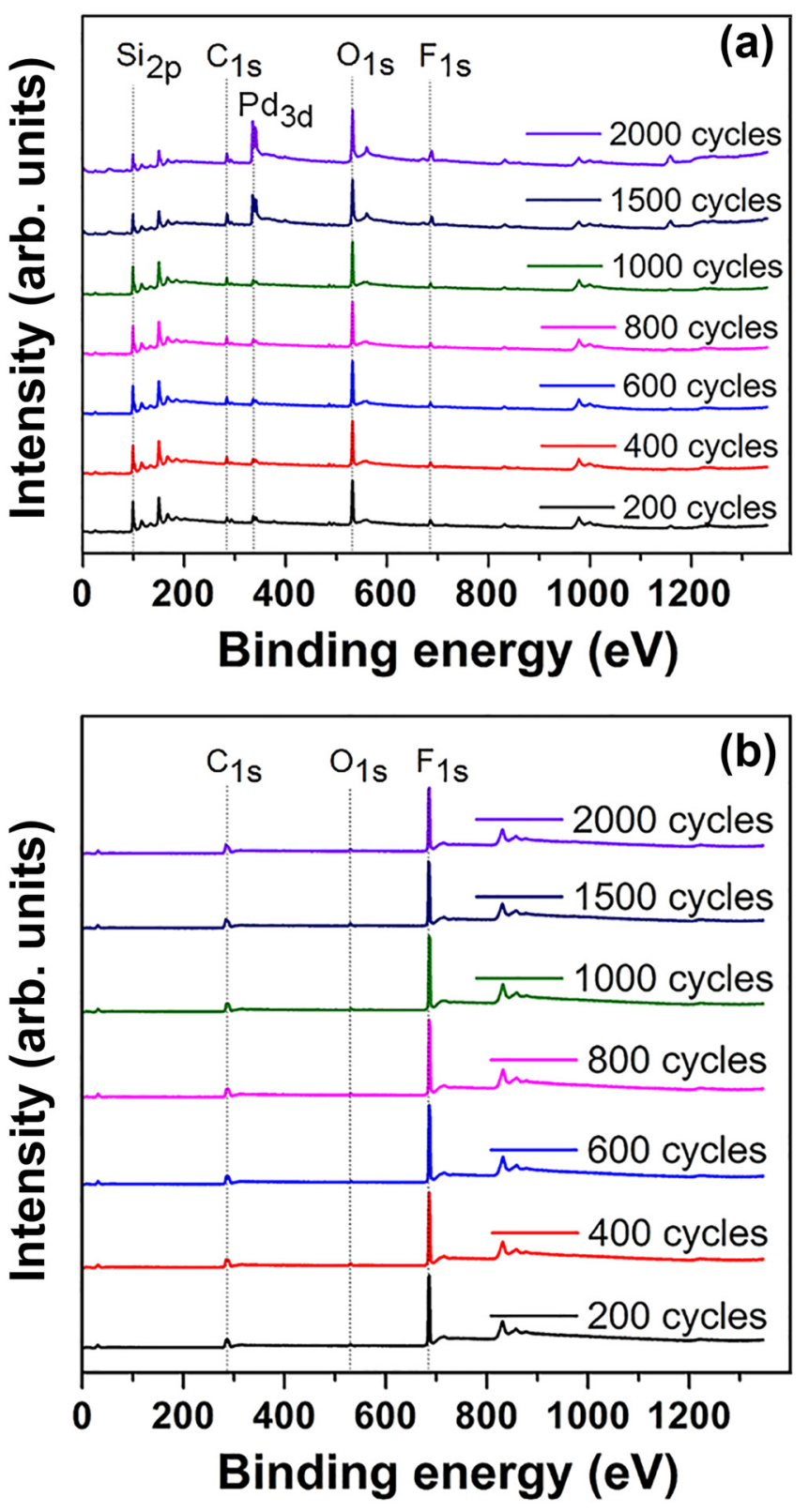

FIG. 10. XPS survey scans of (a) $\mathrm{Si}(100)$ and (b) $\mathrm{CF}_{\mathrm{x}} / \mathrm{Si}$ samples at various stages of Pd-ALD growth experiments, which confirm effective Pd-nucleation blocking of the $\mathrm{CF}_{\mathrm{x}}$ surface up to 2000 Pd-ALD cycles. 
relatively strong C-F bonding that prevented any film etching reaction during excessively long ozone exposure at temperatures up to $150{ }^{\circ} \mathrm{C}$. In addition to the inherent unreactive nature of $\mathrm{CF}_{\mathrm{x}}$, stability in the thickness of the $\mathrm{CF}_{\mathrm{x}}$ layers indicates the potential for a further investigation of AS-ALD under alternate energetic coreactants and plasma chemistries in radical-assisted ALD processes.

The structural properties of the Pt film were studied by GIXRD. Figures 5(a) and 5(b) depict the XRD pattern and SEM image of the as-prepared Pt film with $\sim 20 \mathrm{~nm}$ thickness. The measured pattern was indexed by a fcc crystal system (ICDD reference
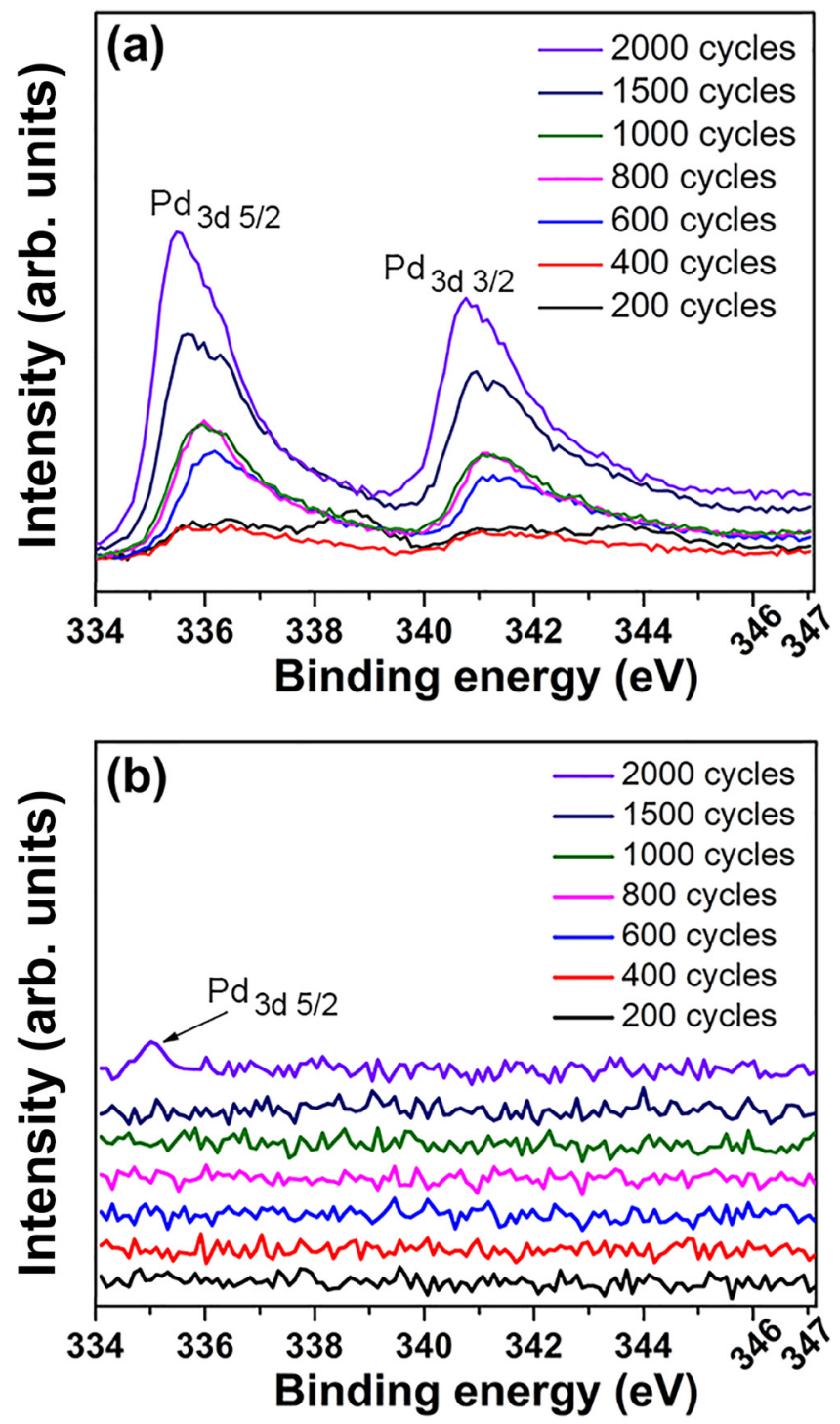

FIG. 11. HR-XPS survey scans of Pd $3 d$ obtained at different stages of Pd-ALD on (a) Si (100) and (b) $\mathrm{CF}_{x} / \mathrm{Si}$ (100), confirming the near-ideal complete blocking of $\mathrm{Pd}$ deposition on the $\mathrm{CF}_{\mathrm{x}}$ surface. code: 00-004-0802). The (111), (200), (220), (311), and (222) peak reflections were observed at the $2 \theta$ values of $40.2^{\circ}, 46.6^{\circ}$, $67.9^{\circ}, 81.9^{\circ}$, and $86.3^{\circ}$, respectively. The XRD peaks of the Pt thin film were comparable to those of the corresponding bulk Pt material. ${ }^{49}$ The lattice parameter $a$ was calculated using $2 \theta$ positions of the (111) reflection. Interplanar spacing $\left(d_{h k l}\right)$ values were calculated from Bragg's law and the $a$-axis lattice parameter was calculated as $\sim 3.88 \AA$, which matches well with the bulk value for Pt (3.92 ̊̊).

\section{Selective Pt deposition and self-aligned patterning}

Self-aligned patterning of $\mathrm{Pt}$ films is demonstrated using selective $\mathrm{Pt}$ deposition on lithographically patterned $\mathrm{CF}_{\mathrm{x}} / \mathrm{Si}$ samples with 180 Pt-ALD cycles and by EDX analysis, XPS line scan
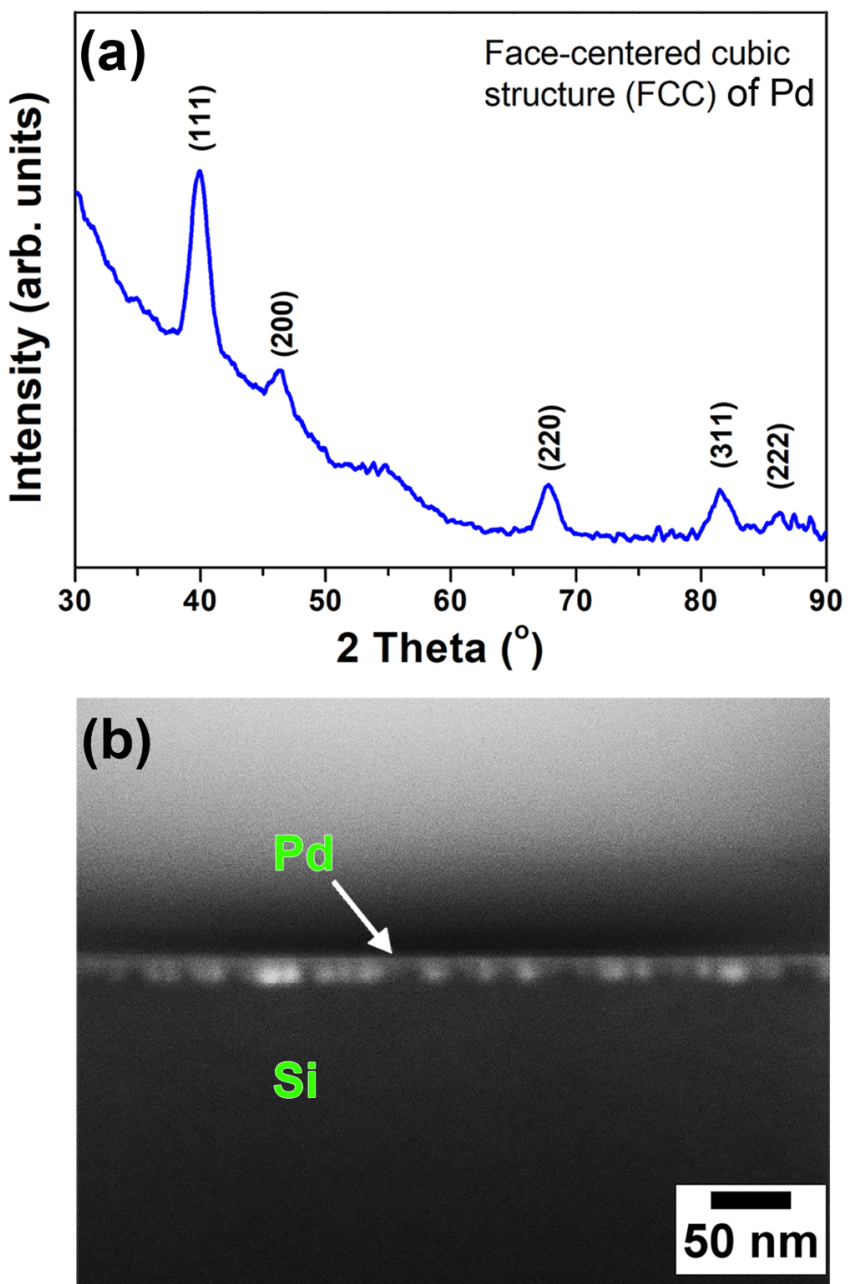

FIG. 12. (a) GIXRD pattern of Pd film selectively deposited on the Si (100) substrate at $200^{\circ} \mathrm{C}$. (b) Cross-sectional HR-SEM image of the Pd/Si sample with the $\sim 15 \mathrm{~nm}$ thick Pd film. 
measurements, and HR-SEM imaging, as shown in Figs. 6(a)-6(c). An XPS line scan was performed on mm-scale $\mathrm{Pt}$ patterns [Fig. 6(a)] where Pt $4 \mathrm{f}$ intensity was measured [Fig. 6(b)]. The Pt $4 \mathrm{f}$ peak is observed only in bright-looking regions where the $\mathrm{CF}_{\mathrm{x}}$ layer was lifted off with the $\mathrm{Si}$ (100) growth surface exposed, while $\mathrm{CF}_{\mathrm{x}}$ regions with a dark color contrast exhibit Pt $4 \mathrm{f}$ intensity as a background (noise-floor) signal, confirming the absence of Pt deposition on the $\mathrm{CF}_{\mathrm{x}}$ nongrowth surface. The reason for a gradual increase in $\mathrm{Pt} 4 \mathrm{f}$ intensity at the $\mathrm{CF}_{\mathrm{x}} / \mathrm{Si}(100)$ boundaries can be attributed to the relatively larger spot size of the monochromatized Al K $\alpha$ x-ray source that was set to $\sim 100 \mu$ m during the XPS line scan, as well as the value of scanning steps and a number of scanning points utilized. At the $\mathrm{CF}_{\mathrm{x}} / \mathrm{Pt}$ interface, due to the relatively large XPS spot size, we simultaneously detect signals from both $\mathrm{CF}_{\mathrm{x}}$ and $\mathrm{Pt}$ covered surfaces, which cause a gradual increase in the observed Pt intensity. The uniform blocking of Pt growth on the $\mathrm{CF}_{\mathrm{x}}$ pattern was confirmed by the HR-SEM image, which depicts a sharp $\mathrm{CF}_{\mathrm{x}} / \mathrm{Pt}$ interface [see Fig. 6(a)]. Figure 6(c) shows the EDX line scan measurement, revealing Pt $\mathrm{M} \mathrm{x}$-ray quanta being detected along the scan line. As expected, the intensity of Pt M x-ray quanta increases only in line patterns where $\mathrm{CF}_{\mathrm{x}}$ was lifted off with the exposed Si (100) surface, which reaffirms the effective self-aligned patterning of $\mathrm{Pt}$ line structures at the micro scale.

EDX elemental mapping images are shown in Fig. 7; this mapping is performed to indicate the coverage and distribution of $\mathrm{Pt}, \mathrm{C}$, and $\mathrm{F}$ elements on the patterned $\mathrm{CF}_{\mathrm{x}} / \mathrm{Si}$ sample surface. Figure 7(a) shows the SEM image of patterned Pt line features through which elemental maps of $\mathrm{Pt}, \mathrm{C}$, and $\mathrm{F}$ are collected. Figures 7 (b) -7 (d) show the elemental maps of C K, Pt M, and F K, respectively. These results confirm both successful self-aligned patterning of $\mathrm{CF}_{\mathrm{x}}$ and area-deactivated AS-ALD deposition of Pt up to at least 180 ALD cycles. We have used 180 cycles of Pt-ALD to avoid any Pt nucleation that appeared after 200 growth cycles and to demonstrate optimal conditions for Pt nucleation on the $\mathrm{Si}$ growth surface, while the $\mathrm{CF}_{\mathrm{x}}$ nongrowth surface shows near-ideal nucleation blocking.

\section{B. Pd nucleation and selectivity}

\section{Pd nucleation: $C F_{x}$ versus Si (100) surfaces}

The Pd-ALD growth experiments using $\mathrm{Pd}(\mathrm{hfac})_{2}$ and formaline precursors were carried out on $\mathrm{CF}_{\mathrm{x}}$-coated and bare $\mathrm{Si}(100)$ substrates for $200,400,600,800,1000,1500$, and 2000 ALD cycles. Figures 8(a) and 8(b) depict the variation in the measured contact angle and average Pd-cluster size of the exposed substrates as a function of the number of ALD cycles. At the end of the first 200 Pd-ALD cycles, the contact angle of the Si sample decreased from $\sim 71^{\circ}$ to $\sim 57^{\circ}$, while the $\mathrm{CF}_{\mathrm{x}}$-coated sample exhibited only a slight decrease from $\sim 114^{\circ}$ to $\sim 110^{\circ}$. With a further increase in ALD cycles up to 2000 cycles on $\mathrm{Si}$ (100) samples, the contact angle exhibited an increase and fluctuated between $\sim 68^{\circ}$ and $72^{\circ}$. The increase of the contact angle with increasing the number of ALD cycles [Fig. 8(a)] can be attributed to the topography [the impact of the surface roughness due to the changes in palladium nanoparticle dimensions (Fig. 8(b)]..$^{50,51}$ In contrast, $\mathrm{CF}_{\mathbf{x}}$ samples exhibited a rather stable contact angle value of $\sim 109^{\circ}$, almost independent from the number of ALD cycles up to 1000 cycles. However, the contact angle decreased to $\sim 95^{\circ}$ for Pd growth cycles higher than 1500 , signaling a possible nucleation onset for Pd film growth on the $\mathrm{CF}_{\mathrm{x}}$ surface. These results indicate that the plasma-polymerized $\mathrm{CF}_{\mathrm{x}}$ layer retains its rather hydrophobic and inert character up to more than 1000 Pd-ALD cycles, while its surface state starts to show an initial change toward 1500 ALD cycles.

Subsequently, SEM measurements were performed to visualize the nucleation behavior of $\mathrm{Pd}$ on $\mathrm{CF}_{\mathrm{x}}$-coated and bare $\mathrm{Si}$ (100) sample surfaces. Figures $9(\mathrm{a})-9(\mathrm{j})$ represent HR-SEM images of Pd-ALD on bare and $\mathrm{CF}_{\mathrm{x}}$-coated $\mathrm{Si}$ (100) samples after 200, 600, 1000,1500 , and 2000 ALD cycles, respectively. In agreement with the contact angle measurements, HR-SEM images apparently show no measurable evidence of $\mathrm{Pd}$ growth on the $\mathrm{CF}_{\mathrm{x}}$ surface up to the maximum 2000 ALD cycles that we have studied. This is in strong contrast to Pd nucleation and growth behavior on Si (100), where $\mathrm{Pd}$ nucleates right away and Pd-NPs are apparent after the first 200

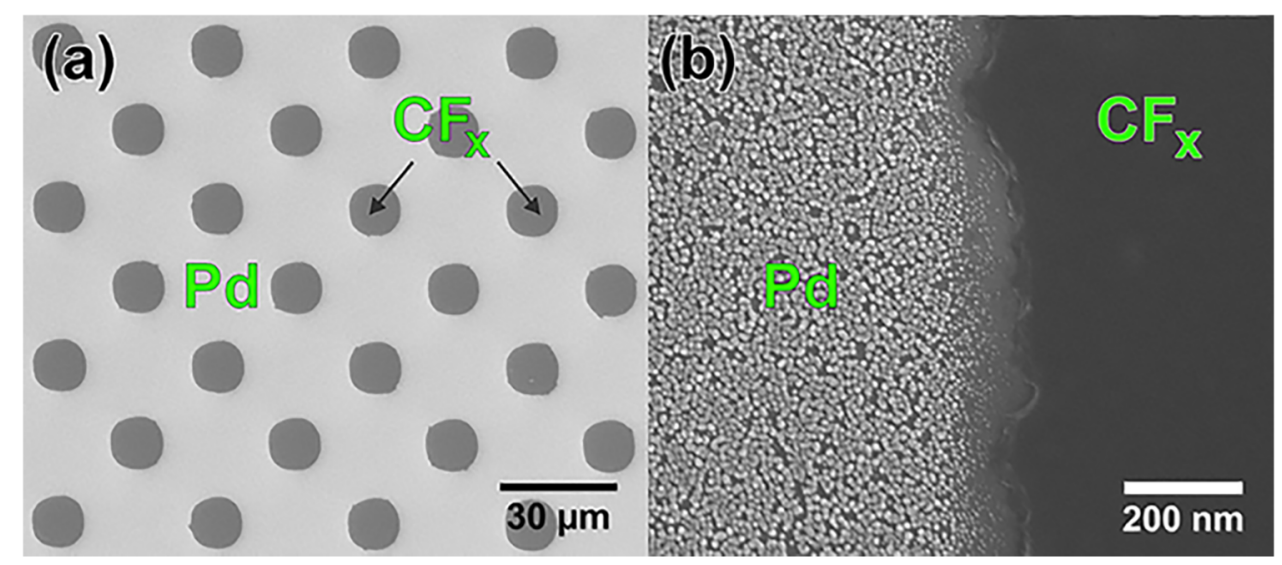

FIG. 13. SEM and HR-SEM images of the patterned $\mathrm{CF}_{x} / \mathrm{Si}$ sample surface after 2000 cycles of Pd-ALD. (a) SEM image showing the contrast of Pd-coated Si (100) and uncoated $\mathrm{CF}_{\mathrm{x}}$ regions. (b) HR-SEM image of the $\mathrm{Pd} / \mathrm{CF}_{\mathrm{x}}$ interface, which demonstrates the absence of Pd nucleation on the ICP-polymerized $\mathrm{CF}_{\mathrm{x}}$ blocking layer. 
ALD cycles. A further increase in Pd growth cycles on Si (100) leads to an increase in the density and size of Pd-NPs, eventually coalescing into larger and densely packed Pd islands, with an estimated effective film thickness of $\sim 10 \mathrm{~nm}$. On the other hand, the polymerized $\mathrm{CF}_{\mathrm{x}}$ film retained its growth blocking character until the testing of the maximum number (2000) of growth cycles. Literature reports indicate that organic blocking layers used for selective ALD exhibit degradation beyond a certain number of ALD growth cycles, eventually resulting in unwanted nucleation and failure to block film growth. This result has, in part, been attributed to cumulatively long exposures of the organic blocking layers to relatively high substrate temperatures. Although the $\mathrm{CF}_{\mathrm{x}}$ layer showed significant inhibition against Pd growth up to 2000 ALD cycles $\left(12 \mathrm{~h}\right.$ exposure at $\left.200^{\circ} \mathrm{C}\right)$, it does not imply that $\mathrm{CF}_{\mathrm{x}}$ will not fail eventually. These results are achieved without a detailed and systematic recipe optimization for Pd growth since the main aim of this study was to explore the noble metal nucleation inhibition properties of the polymerized $\mathrm{CF}_{\mathrm{x}}$ layers. As a follow-up study, the ALD growth conditions might be further adjusted to achieve enhanced selectivity performance via shorter unit ALD cycles.

Table II summarizes the quantification of the Pd content (at. \%) from XPS survey scans for $\mathrm{Pd}$ on $\mathrm{CF}_{\mathrm{x}} / \mathrm{Si}$ and bare $\mathrm{Si}$ (100) substrates. Other than the $\mathrm{Pd}$ content, information related to the elemental composition of $\mathrm{Si}, \mathrm{C}, \mathrm{O}$, and $\mathrm{F}$ is presented in Table SIV in the supplementary material. ${ }^{56}$ The amount of $\mathrm{Pd}$ on the $\mathrm{CF}_{\mathrm{x}} / \mathrm{Si}$ samples was calculated as $\sim 0.02 \%$ using XPS data, regardless of the number of ALD cycles up to 1500 cycles. This result again confirms that $\mathrm{CF}_{\mathrm{x}}$ is efficiently blocking Pd nucleation for at least 1500 ALD cycles. With an additional 500 cycles, the 2000-cycle Pd-ALD sample on the $\mathrm{CF}_{\mathrm{x}} / \mathrm{Si}$ substrate indicates a slight but yet observable increase to $\sim 0.12 \%$. Despite the fact that this atomic percentage corresponds to typically less than a monolayer of Pd deposition, we can safely claim that the complete $\mathrm{Pd}$-nucleation blocking property of ICP-polymerized $\mathrm{CF}_{\mathrm{x}}$ is degraded after 2000 cycles of Pd-ALD. The Pd content on bare Si (100) substrate samples, on the other hand, shows a strongly correlated increase with a number of ALD growth cycles, confirming the absence of Pd nucleation inhibition of Si surfaces.

XPS survey scan data from both $\mathrm{Si}$ and $\mathrm{CF}_{\mathrm{x}}$ samples were recorded at various growth stages to determine the surface elemental composition as well as the chemical bonding states (see Fig. 10). $\mathrm{C} 1 \mathrm{~s}, \mathrm{O} 1 \mathrm{~s}$, and $\mathrm{F} 1 \mathrm{~s}$ peaks were detected from the $\mathrm{CF}_{\mathrm{x}}$ surface, irrespective of the number of Pd-ALD cycles. The absence of the as detectable $\mathrm{Pd} 3 \mathrm{~d}$ peak corroborates the previous findings that $\mathrm{CF}_{\mathrm{x}}$ successfully blocks Pd film growth throughout the 2000 ALD cycles [Fig. 10(b)]. On the other hand, on the bare Si (100) surface, the presence of relatively strong $\mathrm{Pd} 3 \mathrm{~d}$ peak signals right after the very first 200 ALD cycles confirms the Si (100) surface as an efficient growth surface with no or small nucleation delay [Fig. 10(a)].

To further analyze and confirm Pd nucleation inhibition on the $\mathrm{CF}_{\mathrm{x}}$ surface, $\mathrm{Pd} 3 \mathrm{~d}$ high-resolution XPS (HR-XPS) scans were carried out, and the resulting peak spectra measured on Si (100) and $\mathrm{CF}_{\mathrm{x}} / \mathrm{Si}(100)$ as a function of total ALD cycles are shown in Fig. 11. All recorded peaks were fitted after a charge correction with respect to the adventitious $\mathrm{C} 1 \mathrm{~s}$ spectra component $(\mathrm{C}-\mathrm{C}, \mathrm{C}-\mathrm{H})$, with the binding energy set to $284.8 \mathrm{eV}$. HR-XPS spectra exhibit Pd $3 \mathrm{~d} 5 / 2$ and $\mathrm{Pd} 3 \mathrm{~d} 3 / 2$ spin-orbit doublet peaks for the ALD-grown Pd (a)
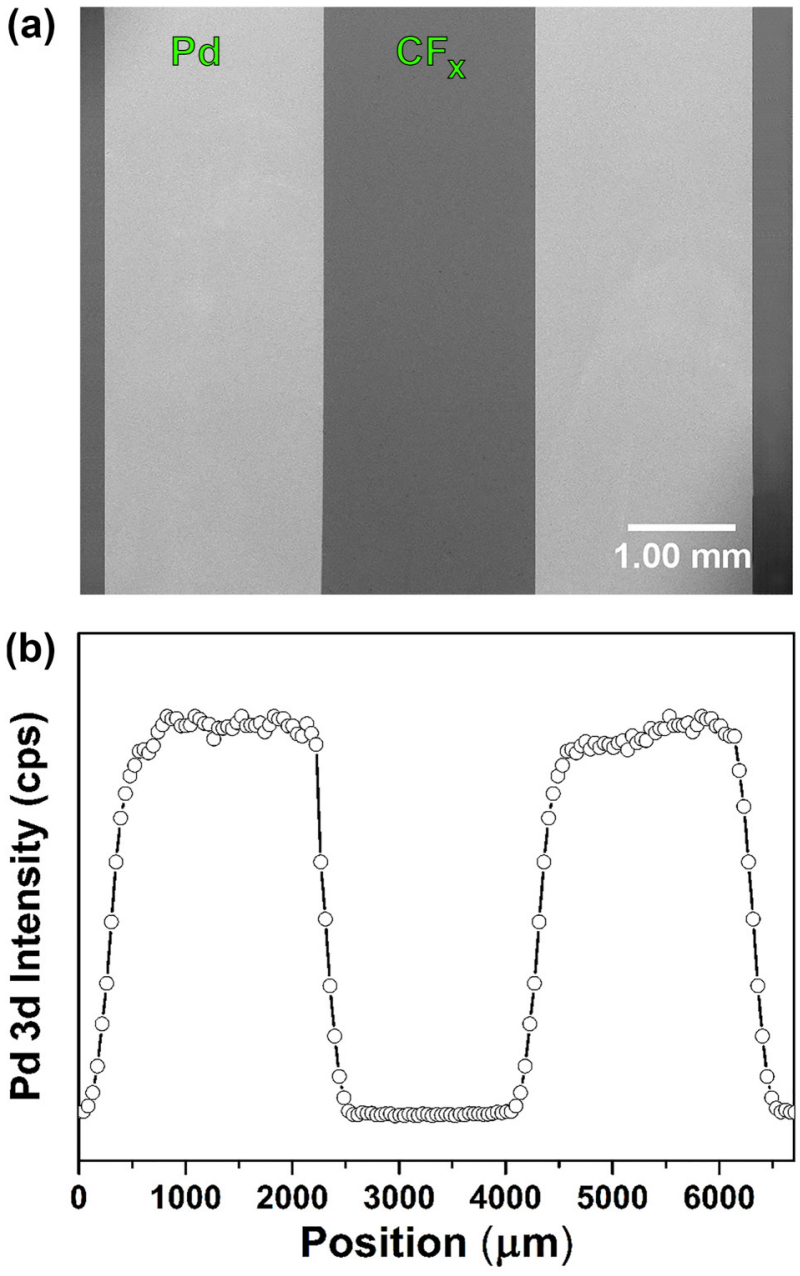

(c)

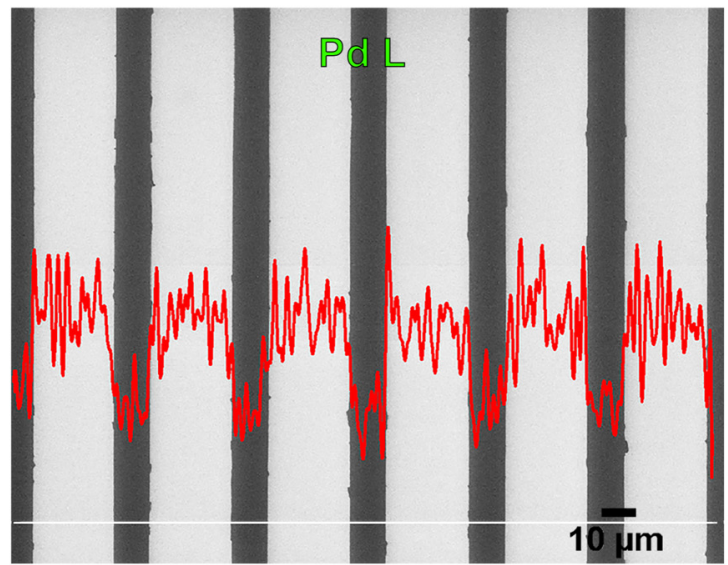

FIG. 14. (a) and (b) SEM image and XPS Pd $3 d$ line scan measurements obtained from 2000 cycle Pd-ALD samples grown on mm-scale patterned $\mathrm{CF}_{\mathrm{X}} /$ Si (100) features, respectively. (c) EDX Pd L line scan superposed on the SEM image obtained from the $\mu \mathrm{m}$-scale $\mathrm{CF}_{x} / \mathrm{Si}(100)$ patterned sample after 2000 Pd-ALD cycles. 
on bare Si (100) substrates, which represent the growth surface for our experiments. The detected bonding species, their corresponding spectral lines, and binding energy values for the grown Pd film have been summarized in Table SV in the supplementary material. ${ }^{56}$ For the initial 200 and 400 growth cycles, $\mathrm{Pd}-\mathrm{O}$ and $\mathrm{Pd}-\mathrm{O}_{\mathrm{x}}$ bonding schemes have also been detected in addition to the main $\mathrm{Pd}-\mathrm{Pd}$ core level bonding. Figure 11(a) shows that beyond 400 growth cycles, Pd 3d5/2 and $\mathrm{Pd} 3 \mathrm{~d} 3 / 2$ peaks corresponding only to Pd-Pd bonding interactions have been detected, confirming the formation of small Pd clusters leading to larger Pd agglomerations and eventually Pd thin films with complete surface coverage. ${ }^{52,53}$ On the contrary, no detectable Pd signal is observed in the HR-XPS data obtained from the $\mathrm{CF}_{\mathrm{x}} / \mathrm{Si}$ samples [Fig. 11(b)] from which it can be inferred that there is nearideal Pd nucleation inhibition on the $\mathrm{CF}_{\mathrm{x}}$ blocking layers up to 2000 ALD cycles.

Figure 12 displays the XRD pattern and SEM image of the as-prepared $\sim 15 \mathrm{~nm}$ thin film, showing the characteristic of the property of crystalline $\mathrm{Pd}$. The exhibited pattern was indexed by the fcc crystal system (ICDD reference code: 00-046-1043). The (111), (200), (220), (311), and (222) peak reflections were observed at the $2 \theta$ values of $39.9^{\circ}, 46.4^{\circ}, 67.7^{\circ}, 81.4^{\circ}$, and $86.2^{\circ}$, which are in agreement with previously reported results. ${ }^{54}$ The lattice parameter $a$ was similarly calculated using $2 \theta$ positions of (111) reflection. The extracted $a$-axis lattice parameter was $3.91 \AA$, which matches well with the bulk lattice parameter value for Pd $(3.89 \AA) .{ }^{55}$

\section{Selective Pd deposition and self-aligned patterning}

Similar to our selective Pt deposition study, we carried out self-aligned $\mathrm{Pd}$ film patterning experiments via selective Pd deposition on lithographically patterned $\mathrm{CF}_{\mathrm{x}} / \mathrm{Si}$ substrates. Positive $\mathrm{CF}_{\mathrm{x}}$ patterns were formed for the analysis and visualization of possible edge effects in selective Pd growth on Si (100) and growth inhibition on $\mathrm{CF}_{\mathrm{x}}$, respectively. Pd deposition was carried out for 2000 ALD cycles on patterned $\mathrm{CF}_{\mathrm{x}} / \mathrm{Si}$ samples, which are subsequently characterized by HR-SEM, EDX line-scan, EDX elemental mapping, and XPS line scan measurements. Figures 13(a) and 13(b) show SEM images of the Pd patterns, which legibly indicate the selective deposition of the Pd metal (brighter regions) along with a clear and uncoated $\mathrm{CF}_{\mathrm{x}}$ surface (darker circular spots). The HR-SEM image from the $\mathrm{Pd} / \mathrm{CF}_{\mathrm{x}}$ interface shows no $\mathrm{Pd}$ deposition signs on top of the polymerized $\mathrm{CF}_{\mathrm{x}}$ patterns, except a narrow transition region $(50-100 \mathrm{~nm})$ corresponding to the width of the lifted-off $\mathrm{CF}_{\mathrm{x}}$ layer sidewall. Within these transition areas, $\mathrm{Pd}$ nanoparticles

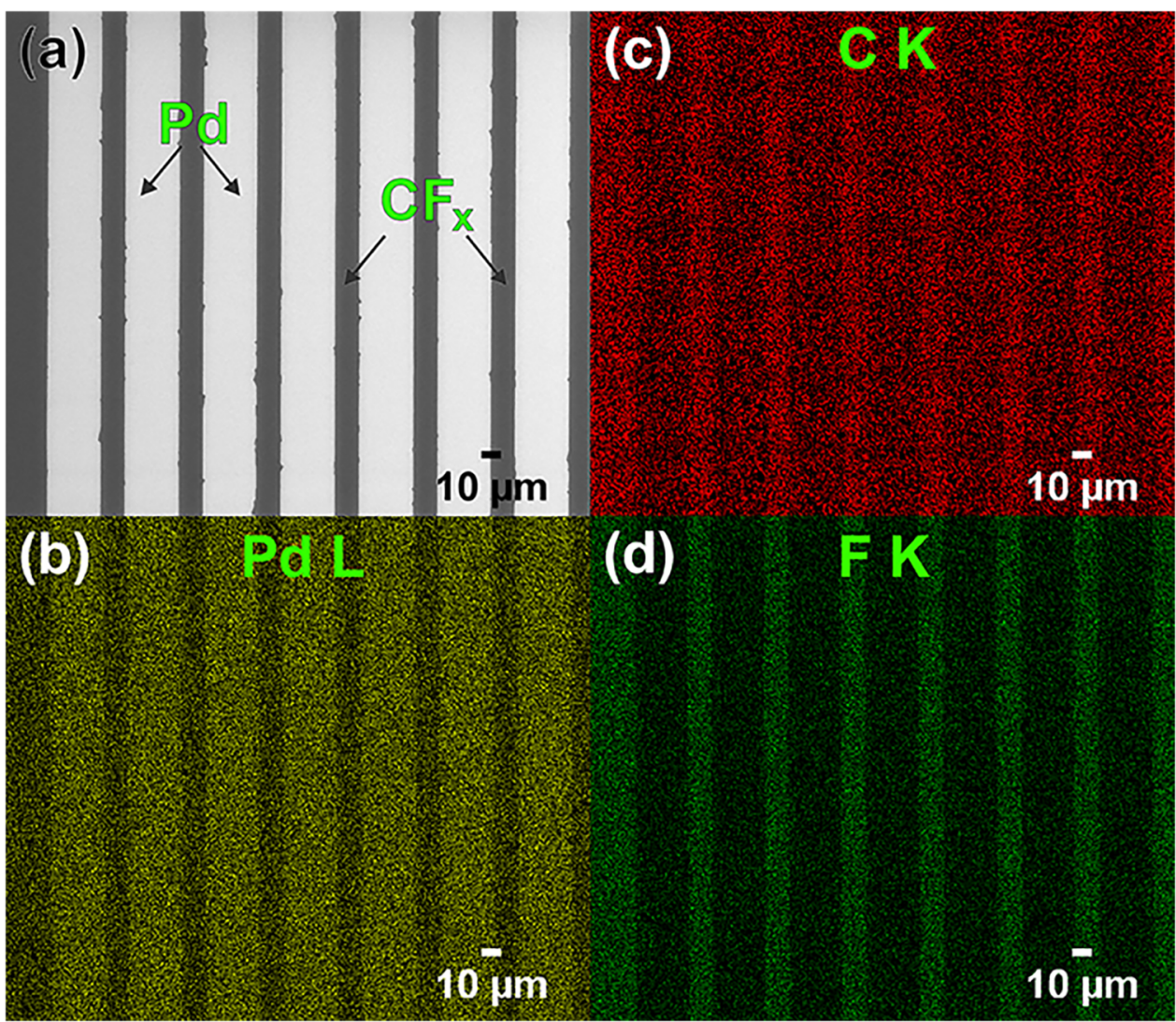

FIG. 15. SEM image of (a) $P d / C F_{x}$ patterned sample after 2000-cycle Pd-ALD experiment. Elemental mapping of (b) $P d L$, (c) $C K$, and (d) $F K$ signals. 
with smaller cluster size and lower density are observed most probably due to the imperfections of the conventional photolithographic patterning process.

To analyze the elemental composition variation along the $\mathrm{Pd} / \mathrm{CF}_{\mathrm{x}}$ patterns, EDX and XPS line scans were performed, as depicted in Fig. 14. The XPS line scan was performed on larger mm-scale Pd patterns [Fig. 14(a)] as the survey spectra for this measurement were recorded with an x-ray beam size of $400 \mu \mathrm{m}$, along with $\sim 50 \mu \mathrm{m}$ steps between each data point. Pd 3d intensity was measured in terms of counts per second versus spatial location along the line [Fig. 14(b)]. A considerable contrast is observed between the Pd $3 \mathrm{~d}$ peak signal intensity obtained from the lifted-off $\mathrm{Si}$ (100) regions where Pd has grown without a significant nucleation delay and $\mathrm{CF}_{\mathrm{x}}$ patterns which blocked Pd nucleation effectively, confirming a signal intensity equal to the noise floor of the XPS system. The EDX line scan [Fig. 14(c)] reveals that the intensity of Pd L $\mathrm{x}$-ray quanta increases only within the non- $\mathrm{CF}_{\mathrm{x}}$-coated line features, which reaffirm the successful self-aligned deposition of Pd via polymerized fluorocarbon growth inhibitors.

Figure 15 represents the EDX elemental mapping analyses of $\mathrm{Pd}, \mathrm{C}$, and $\mathrm{F}$ elements at specific patterned areas after the 2000-cycle ALD experiment. Figure 15(a) shows the SEM image of the patterned Pd line features through which elemental maps of Pd, C, and F are collected. Figures 15(b)-15(d) depict the elemental maps of $\mathrm{C} \mathrm{K}, \mathrm{Pd} \mathrm{L}$, and F K, respectively. It is evident from these elemental maps that $\mathrm{Pd}$ is present only in the line features that coincide with the $\mathrm{Pd}$ lines covering the non- $\mathrm{CF}_{\mathrm{x}}$-coated regions shown in Fig. 15(a). Overall, XPS, EDX line scan, and EDX elemental mapping cumulatively confirm the successful self-aligned patterning via selective Pd deposition using 2000-cycle ALD on lithographically patterned samples.

\section{SUMMARY AND CONCLUSIONS}

In conclusion, we have presented a systematic investigation on the growth blocking/inhibition efficacy of plasma-polymerized $\mathrm{CF}_{\mathrm{x}}$ layers to achieve selective deposition of $\mathrm{Pt}$ and $\mathrm{Pd}$. We have demonstrated an effective yet relatively simple approach for low-temperature self-aligned patterning of $\mathrm{Pt}$ and Pd films using a CMOS-compatible plasma-polymerization process. The recorded nucleation delays for Pt and Pd correspond to equivalent blocking thicknesses of $\sim 20$ and $\sim 15 \mathrm{~nm}$, respectively, with selectivity values of $\sim 0.99$ for both $\mathrm{Pt}$ and $\mathrm{Pd}$ depositions. This work confirms that plasma-polymerized $\mathrm{CF}_{\mathrm{x}}$ layers effectively inhibit film growth not only for certain oxide compounds but also for widely used noble metals ( $\mathrm{Pt}$ and $\mathrm{Pd}$ ). The reason for $\mathrm{CF}_{\mathrm{x}}$ blocking layer degradation during the ozone-based ALD process was concluded to be due to the oxygen physisorption with further hydroxyl group formation on the $\mathrm{CF}_{\mathrm{x}}$ surface that creates the favorable nucleation sites for Pt growth initiation. Our methodology can be utilized for various 3D device structures where selective $\mathrm{Pt} / \mathrm{Pd}$ deposition on horizontal surfaces might be critically needed while blocking other inclined and vertical surfaces via conformally coated $\mathrm{CF}_{\mathrm{x}}$ blocking layers. Moreover, the ozone-compatible selective deposition capability might pave the way for the AS-ALD of a wider set of materials that can benefit from ozone and alternate energetic coreactants.

\section{ACKNOWLEDGMENTS}

The authors acknowledge the Institute of Materials Science and Nanotechnology (UNAM), Bilkent University, for the growth and material characterization facilities, TUBITAK for their support under 2216 project for International Researcher, and the University of Connecticut-Research Excellence Program (REP) Grant funded by the Office of the Vice President for Research (OVPR).

\section{DATA AVAILABILITY}

The data that support the findings of this study are available from the corresponding author upon reasonable request.

\section{REFERENCES}

'S. F. Bent, ASD 2017, Eindhoven, The Netherlands, 20-21 April 2017 (2017)

${ }^{\mathbf{2}}$ W.-H. Kim et al., ACS Nano 10, 4451 (2016).

${ }^{3}$ J. Singh, N. F. W. Thissen, N. F. W. Thissen, W. H. Kim, H. Johnson, W. M. M. Kessels, A. Bol, S. F. Bent, and A. J. M. Mackus, Chem. Mater. 30, 663 (2018).

${ }^{4}$ E. Färm, M. Kemell, M. Ritala, and M. Leskelä, Thin Solid Films 517, 972 (2008).

${ }^{5}$ E. Stevens, Y. Tomczak, B. T. Chan, E. A. Sanchez, G. N. Parsons, and A. Delabie, Chem. Mater. 30, 3223 (2018).

${ }^{6}$ S. M. George, Chem. Rev. 110, 111 (2010).

${ }^{7}$ M. Leskela and M. Ritala, Thin Solid Films 409, 138 (2002).

${ }^{8}$ C. J. Serpell, J. Cookson, D. Ozkaya, and P. D. Beer, Nat. Chem. 3, 478 (2011).

${ }^{9}$ A. J. M. Mackus, D. et al., Chem. Mater. 25, 1769 (2013).

10J. Hämäläinen, F. Munnik, M. Ritala, and M. Leskelä, Chem. Mater. 20, 6840 (2008).

${ }^{11}$ M. Knez, K. Nielsch, and L. Niinisto, Adv. Mater. 19, 3425 (2007).

${ }^{12}$ M. D. Groner, F. H. Fabreguette, J. W. Elam, and S. M. George, Chem. Mater. 16, 639 (2004).

${ }^{13}$ B. S. Lim, A. Rahtu, and R. G. Gordon, Nat. Mater. 2, 749 (2003).

${ }^{14}$ J. Tang, Q. Cao, G. Tulevski, K. A. Jenkins, L. Nela, D. B. Farmer, and S.-J. G. Han, Nat. Electron. 1, 191 (2018).

${ }^{15}$ A. J. M. Mackus, A. A. Bol, and W. M. M. Kessels, Nanoscale 6, 10941 (2014).

${ }^{16}$ K. Cao, J. Cai, X. Liu, and R. Chen, J. Vac. Sci. Technol. A 36, 010801 (2018).

${ }^{17}$ S. Seo et al., ACS Appl. Mater. Interfaces 9, 41607 (2017).

${ }^{18}$ A. Mameli, M. J. M. et al., ACS Nano 11, 9303 (2017).

${ }^{19}$ C. R. Ellinger and S. F. Nelson, Chem. Mater. 26, 1514 (2014).

${ }^{20}$ M. Junige, M. Löffler, M. Geidel, M. Albert, J. W. Bartha, E. Zschech, B. Rellinghaus, and W. F. van Dorp, Nanotechnology 28, 395301 (2017).

${ }^{21}$ K. J. Park and G. N. Parsons, Appl. Phys. Lett. 89, 043111 (2006).

${ }^{22}$ X. R. Jiang, H. Huang, F. B. Prinz, and S. Bent, Chem. Mater. 20, 3897 (2008).

${ }^{23}$ A. J. M. Mackus, S. A. F. Dielissen, J. J. L. Mulders, and W. M. M. Kessels, Nanoscale 4, 4477 (2012).

${ }^{24}$ J. Hong, D. W. Porter, R. Sreenivasan, P. C. McIntyre, and S. Bent, Langmuir 23, 1160 (2007).

${ }^{\mathbf{2 5}}$ M. H. Park, Y. J. Jang, H. M. Sung-Suh, and M. M. Sung, Langmuir 20, 2257 (2004).

${ }^{26}$ J. R. Avila, E. J. Demarco, J. D. Emery, O. K. Farha, M. J. Pellin, J. T. Hupp, and A. B. F. Martinson, ACS Appl. Mater. Interfaces 6, 11891 (2014).

${ }^{27}$ F. Sadat, M. Hashemi, B. R. Birchansky, and S. F. Bent, ACS Appl. Mater. Interfaces 8, 33264 (2016).

${ }^{28}$ J.-Y. Kim, D.-S. Kil, J.-H. Kim, S.-H. Kwon, J.-H. Ahn, J.-S. Roh, and S.-K. Park, Electrochem. Soc. 159, H560 (2012).

${ }^{29}$ J. Hämäläinen, M. Ritala, and M. Leskelä, Chem. Mater. 26, 786 (2014).

${ }^{30}$ Z. Chen, J. Appenzeller, J. Knoch, Y. Lin, and P. Avouris, Nano Lett. 5, 1497 (2005). 
${ }^{31}$ A. Javey, J. Guo, Q. Wang, M. Lundstrom, and H. Dai, Nature 424, 654 (2003).

${ }^{32} \mathrm{X}$. Luo et al., Nanotechnology 26, 164003 (2015).

${ }^{33}$ Y. Jiang, J. Chen, J. Zhang, A. Li, Y. Zeng, F. Zhou, G. Wanga, and R. Wang, RSC Adv. 6, 13207 (2016).

${ }^{34}$ D. Gu, H. Baumgart, K. Tapily, P. Shrestha, G. Namkoong, X. Ao, and F. Müller, Nano Res. 4, 164 (2011).

${ }^{35} \mathrm{~K}$. Kim et al., Nat. Commun. 5, 4781 (2014).

${ }^{36}$ S. Fleischmann, A. Tolosa, M. Zeiger, B. Kruner, N. J. Peter, I. Grobelsek, A. Quade, A. Kruthd, and V. Presser, J. Mater. Chem. A 5, 2792 (2017).

${ }^{37}$ K. Cao, Q. Zhu, B. Shan, and R. Chen, Sci. Rep. 5, 8470 (2015).

${ }^{38}$ A. J. M. Mackus, J. J. L. Mulders, M. C. M. Sanden, and W. M. M. Kessels, J. Appl. Phys. 107, 116102 (2010).

${ }^{39}$ R. H. J. Vervuurt, A. Sharma, Y. Jiao, W. M. M. Kessels, and A. Bol, Nanotechnology 27, 405302 (2016).

${ }^{40}$ A. Haider, P. Deminskyi, T. M. Khan, H. Eren, and N. Biyikli, J. Phys. Chem. C 120, 26393 (2016).

${ }^{41}$ A. Haider, M. Yilmaz, P. Deminskyi, H. Eren, and N. Biyikli, RSC Adv. 6, 106109 (2016).

${ }^{42}$ T. Aaltonen, M. Ritala, Y.-L. Tung, Y. Chi, K. Arstila, K. Meinander, and M. Leskelä, J. Mater. Res. 19, 3353 (2004).

${ }^{43}$ J. J. Senkevich, G.-R. Yang, T.-M. Lu, T. S. Cale, C. Jezewski, and W. A. Lanford, Chem. Vap. Depos. 8, 189 (2002).
${ }^{44}$ I. Dendooven, R. K. Ramachandran, K. Devloo-Casier, G. Rampelberg, M. Filez, H. Poelman, G. B. Marin, E. Fonda, and C. Detavernier, J. Phys. Chem. C 117, 20557 (2013).

${ }^{45}$ J. W. Elam, A. Zinovev, C. Y. Han, H. H. Wang, U. Welp, J. N. Hryn, and M. J. Pellin, Thin Solid Films 515, 1664 (2006).

${ }^{46} \mathrm{M}$. Peukert, Electrochim. Acta 29, 1315 (1984).

${ }^{47}$ T. Nakamura, S. Ichihara, and T. Den, ECS Trans. 3, 275 (2007).

${ }^{48}$ M. Wakisaka, H. Suzuki, S. Mitsui, H. Uchida, and M. Watanabe, J. Phys. Chem. C 112, 2750 (2008).

${ }^{49} \mathrm{~T}$. Ioroi and K. J. Yasuda, Electrochem. Soc. 152, A1917 (2005).

${ }^{50} \mathrm{~B}$. Bhushan and Y. C. Jung, Ultramicroscopy 107, 1033 (2007).

${ }^{51}$ S. Hoshian, V. Jokinen, V. Somerkivi, A. R. Lokanathan, and S. Franssila, ACS Appl. Mater. Interfaces 7, 941 (2015).

${ }^{52}$ K. L. Kelly, E. Coronado, L. L. Zhao, and G. C. Schatz, J. Phys. Chem. B 107, 668 (2003).

${ }^{53}$ D. Astruc, Nanoparticles and Catalysis (Wiley-VCH, New York, 2008).

${ }^{54}$ L. Xu, X.-C. Wu, and J.-J. Zhu, Nanotechnology 19, 305603 (2008).

${ }^{55}$ C. Kittel, Einfuhrung in die Festkorperphysik, R. Oldenbourg Verlag Munchen Wien (Wiley, Frankfurt am Main, 1973), Vol. 128.

${ }^{56}$ See the supplementary material at https://doi.org/10.1116/6.0000701 for XPS survey scan, high-resolution XPS scans, variation in $\mathrm{C}, \mathrm{F}$ at. \% on $\mathrm{CF}_{\mathrm{x}} / \mathrm{Si}$ and $\mathrm{C}$, $\mathrm{Si}$ at. \% as a function of Pt ALD cycles, Pt binding energies on $\mathrm{Si}$ and $\mathrm{CFx} / \mathrm{Si}$, variation in $\mathrm{C}, \mathrm{F}, \mathrm{O}$ at. \% on $\mathrm{CFx} / \mathrm{Si}$ and $\mathrm{C}, \mathrm{Si}$ at. \% on $\mathrm{Si}$ as a function of $\mathrm{Pd}$ ALD cycles, and Pd binding energies. 